\title{
Moisture budget analysis of SST-driven decadal Sahel precipitation variability in the twentieth century
}

\author{
Catherine Pomposi • Yochanan Kushnir • \\ Alessandra Giannini
}

Received: 17 February 2014 / Accepted: 14 October 2014

(C) Springer-Verlag Berlin Heidelberg 2014

\begin{abstract}
It is well known that the Sahel region of Africa is impacted by decadal scale variability in precipitation, driven by global sea surface temperatures. This work demonstrates that the National Center for Atmospheric Research's Community Atmosphere Model, version 4 is capable of reproducing relationships between Sahelian precipitation variability and Indian and Atlantic Ocean sea surface temperature variations on such timescales. Further analysis then constructs a moisture budget breakdown using model output and shows that the change in precipitation minus evaporation in the region is dominated by column integrated moisture convergence due to the mean flow, with the convergence of mass in the atmospheric column mainly responsible. It is concluded that the oceanic forcing of atmospheric mass convergence and divergence to a first order explains the moisture balance patterns in the region. In particular, the anomalous circulation patterns, including net moisture divergence by the mean and transient flows combined with negative moisture advection, together explain the drying of the Sahel during the second half of the twentieth century. Diagnosis of moisture budget and circulation components within the main rainbelt and along the monsoon margins show that changes to the
\end{abstract}

\section{Pomposi $(\bowtie)$}

Department of Earth and Environmental Sciences, Columbia University, 61 Route 9W, 143 Monell, Palisades, NY 10964, USA

e-mail: cpomposi@1deo.columbia.edu

Y. Kushnir

Lamont-Doherty Earth Observatory of Columbia University, 61 Route 9W, 104B Oceanography, Palisades, NY 10964, USA

\section{A. Giannini}

International Research Institute for Climate and Society,

61 Route 9W, 109 Monell, Palisades, NY 10964, USA mass convergence are related to the magnitude of precipitation that falls in the region, while the advection of dry air is associated with the maximum latitudinal extent of precipitation.

Keywords Sahel precipitation $\cdot$ Sea surface temperatures $\cdot$ Atmospheric moisture budget $\cdot$ Monsoon

\section{Introduction}

The West African Monsoon is a robust climatological feature of great importance for the local population living in the region, which depends heavily on seasonal rainfall for agricultural purposes. The monsoon system largely consists of low-level moist flow originating from the nearby Tropical Atlantic Ocean penetrating and converging over the African continent (Fontaine et al. 2008). While intense rainfall events associated with this system begin near the Gulf of Guinea as early as April, the latitudinal band of maximum rainfall does not shift to its northern-most edge until later, usually in late June (Hagos and Cook 2007). It is this stretch of land that traverses the African continent from east-west that is known as the Sahel, extending between approximately $10^{\circ}-18^{\circ} \mathrm{N}$ and separating between the dry Sahara desert to the north with lushly vegetated tropical rainforests to the south, exhibiting a strong gradient in the precipitation field.

Partially due to this complex geography, the Sahel region of Africa exhibits much variability in terms of rainfall. While dry conditions dominate the climatology of the Sahel region throughout the year, a single peak in rainfall occurs as the West African Monsoon invades the region in boreal summer, with high rainfall rates occurring in JulySeptember and the bulk of annual precipitation (Rowell 
et al. 1995). Evidence from both the paleoclimatic and present-day instrumental record indicates that precipitation magnitudes exhibit large-scale variability on a number of timescales (Nicholson 2000; Giannini et al. 2003; Su and Neelin 2005; Shanahan et al. 2009; Otto-Bliesner 1999). Throughout the twentieth century alone Sahel summer precipitation totals have ranged from only 300 to over $700 \mathrm{~mm} /$ year (Nicholson and Webster 2007). Such changes in precipitation have sweeping effects for agricultural and economic interests of the local population, as evident from the massive, prolonged droughts of the 1970s and subsequent famines. Furthermore, recent efforts to model future precipitation changes in the region remain uncertain, with individual Coupled Model Intercomparison Project, phase 5 (CMIP5) models projecting either significant amplifications or decreases in summertime rainfall amounts (Biasutti 2013). Therefore, it is of clear importance to try and understand precipitation variability in the region for both present and future generations to come.

Many previous studies attempted to better understand the reasons for the observed Sahelian precipitation variability throughout the twentieth century. The apparent "shift" in rainfall throughout the region can be described as the 1950s-1960s having greater annual rainfall totals than the century-long mean, while conversely, the 1970s-1980s showed a large decrease in total rainfall. A local "recovery" of the monsoon rains occurred in the 1990s and early years of the twenty-first century (Grist and Nicholson 2001; Nicholson 2005), but there are questions as to whether this is happening throughout the extent of the Sahel or is limited to the central portion of the region (Ali and Lebel 2009; Salack et al. 2011). The large-scale forcing agents of this observed variability in Sahel rainfall have been studied extensively throughout the recent decades and efforts have largely focused on either localized feedbacks and coupling the land surface to atmospheric radiation and air-column stability, or alternatively, on the modulation of Sahel rainfall by global oceanic sea surface temperatures (SSTs). According to a study by Charney (1975), the twentieth century drought in the Sahel was of an anthropogenic origin, where overgrazing by the local pastoralists increased surface albedo, which lead to net radiative cooling of the atmosphere that was compensated by subsidence, thus decreasing precipitation and setting in motion a positive feedback cycle of further vegetation losses and increases in surface albedo. Later work revealed that the suggested land use changes for this explanation were exaggerated and that actually, the changes in vegetation were more likely to be an effect of low precipitation rates rather than a cause (Taylor et al. 2002), or that land-surface feedbacks, while important in understanding precipitation variability in the region worked to amplify the signal imparted by SSTforced variability (Zeng et al. 1999).
Advances in modeling and observational networks revealed as early as the mid-1980s an association between twentieth century rainfall variability in the Sahel and SSTs (Folland et al. 1986; Palmer 1986; Rowell et al. 1995). Giannini et al. (2003) then showed using a global climate model that both low and high frequency characteristics of the observed Sahel drought were simulated by prescribing observed SSTs alone as a boundary condition. Results from this work showed that the Indian Ocean is primarily responsible for decadal-scale variability, with a lesser influence by the Tropical Atlantic Ocean, while high-frequency variability is related to the Pacific Ocean basin and in particular the El Niño/Southern Oscillation region.

Since these initial findings linking SST forcing to modulation of Sahel rainfall, many further studies have detailed the connection of the West African Monsoon to the global oceans on decadal timescales, with subtle differences in their conclusions. Bader and Latif (2003), using the ECHAM4 model conclude that strong warming of the Indian Ocean since the 1950s was predominantly responsible for the twentieth century drought. Lu and Delworth (2005) used the Geophysical Fluid Dynamics Laboratory (GFDL) Atmospheric Model 2 (AM2) forced with global SSTs to show that all tropical oceans appear to contribute to drying in the Sahel, although the impact is larger for the Indian and Pacific Oceans than for the Atlantic. They further note that such a result may be dependent on the model used. Lu (2009) also maintains the dominant role of Indian Ocean warming in driving the twentieth century Sahel drought and provides a suggested mechanism for the teleconnection. Warming in the Indian basin causes enhanced local convection whose latent heat release stabilizes the upper troposphere. Rossby waves carry mid-tropospheric descent to the west of this region of heating, suppressing convection over Africa both due to the sinking motion and to the reduced availability of moisture at the surface resulting from low-level divergence. Hagos and Cook (2008) similarly found effects of the Indian Ocean in forcing the drought and subsidence over Africa. They note that local convergence over the Indian Ocean induces a Rossby wave response and anomalous anticyclonic circulation over West Africa, driving moisture away from the continent. This drying is further enhanced by the tropical Atlantic warm anomaly, which forces convergence over the region, continuing to deplete the supply of moisture to the continent and therefore desiccating the Sahel. On the other hand, Hoerling et al. (2006) using a 40-member Atmosphere General Circulation Model (AGCM) ensemble, failed to reproduce the causal link between Indian Ocean warming and Sahel drying, instead concluding that the relative cooling of the tropical North Atlantic compared with the tropical South Atlantic was the key driver of the twentieth century drought. Finally, Caminade and Terray (2010) 
used the ARPEGE model to conclude that the interhemispheric dipole pattern of SSTs, with the southern hemisphere oceans warming more quickly than the northern hemisphere oceans after 1970, shift the continental rainbelt southward, thus drying the Sahel. They also find some contribution to low frequency drying by the Pacific basin.

Clearly, the relationship between Sahel precipitation variability throughout the twentieth century and global basins' SSTs is robust. What remain unclear are the mechanisms of rainfall variability in the region as driven by SST changes, and in particular the communication of oceanic changes to land. The character of precipitation over land is dependent not only on the locally available moisture via evaporation in the atmospheric column, but also the moisture that is supplied to the region from transport (Brubaker et al. 1993; Trenberth et al. 2003), and thus the local dynamical patterns of convergence or divergence in a region. A full accounting of terms in the moisture budget equation contributes to the interpretation of precipitation variability, specifically by distinguishing between the roles of changes in specific humidity, changes in circulation, and changes in moisture transports by subseasonal eddies (Seager et al. 2010). Notably however, budget consideration should not be interpreted as causal, particularly when discussing tropical convection, where the dynamical components of the budget (moisture flux convergence) are tied to the changes (in space and time) of net moisture at the surface in a strong local diagnostic relationship (Hagos and Zhang 2010).

Here we study the moisture budget associated with the twentieth century Sahelian drought using the SST-forced National Center for Atmospheric Research's (NCAR) Community Atmosphere Model, version 4 (CAM4) (Gent et al. 2011). Specifically, this framework allows for us to answer the following questions:

1. What are the changes in mechanisms of moisture convergence associated with the drying of the Sahel?

2. To what extent did changes in atmospheric circulation affect decadal-scale variability in Sahelian precipitation through the twentieth century?

The manuscript is organized as follows. Section 2 describes the data and methodology used. Section 3 provides an overview of the model's capability to reproduce the twentieth century Sahelian precipitation characteristics and draws comparisons with observations and the National Centers for Environmental Prediction (NCEP)/NCAR Reanalysis. Section 4 provides further support for the model driven analysis, by documenting the SST-teleconnections that are present with model-generated precipitation. Section 5 then details the model climatology and variability for moisture budget variables. In Sect. 6, regressions of the moisture budget terms on the SST index from Sect. 4 are provided to understand the mechanisms of the twentieth century drought as driven by the SST field. Section 7 examines vertical cross sections of the budget terms throughout the rainbelt over West Africa to draw more detailed information regarding the dynamics of the drying. Discussion and conclusions are provided in Sect. 8.

\section{Data and methods}

\subsection{Data}

The data used in this study comes from both observations and a SST-forced AGCM. The observed precipitation dataset used here is from the University of East Anglia's (UEA) Climatic Research Unit (CRU), TS 3.1 (Mitchell and Jones 2005). It is derived from station data, homogenized to correct for potential errors in station reporting, and interpolated to a regular latitude by longitude grid. TS 3.1 precipitation data spatial resolution is $0.5^{\circ}$ and its temporal resolution is monthly. The observed SST data are obtained from The Met Office's Hadley Centre HADISST1 dataset (Rayner et al. 2003). The data have a $1.0^{\circ}$ latitude by longitude spatial resolution and a monthly temporal resolution. Monthly anomalies for both datasets are computed by removing the longterm (1901-2008) climatological values by calendar month. The SST data are also used as the lower-boundary condition to drive the CAM4 model for the years 1901-2008 16-member ensemble runs that vary only in their initial atmospheric conditions. CAM4 was run at the Lamont-Doherty Earth Observatory using these historical global SSTs for previous studies (e.g. Seager et al. 2012). The use of ensemble averaging of the model-generated variables ensures that we emphasize their SST-forced component and reduce the impact of other variations. The ensemble averaged model output utilized in this study includes precipitation, evaporation, sea level pressure (SLP), specific humidity, and wind velocity, of which the latter two variables are also a function of the model vertical grid. Variables are averaged over the peak monsoonal season, defined as July-September (JAS). When taking a spatial average of variables over the Sahel, the bounds used are $10^{\circ}-18^{\circ} \mathrm{N}$ and $15^{\circ} \mathrm{W}-30^{\circ} \mathrm{E}$. In comparing the budget behavior during wet and dry years (in Sect. 7), 15 consecutively wet model years (1925-1939) and 15 consecutively dry model years (1975-1989) before and after the 1968 "shift" are used. In that case the budget terms are averaged in longitude over $10^{\circ} \mathrm{E}-10^{\circ} \mathrm{W}$ to capture their behavior over West Africa.

We also briefly compare the model generated precipitation data to the NCEP/NCAR Reanalysis (Kalnay et al. 1996) precipitation. The NCEP/NCAR Reanalysis uses a forecast system data assimilation procedure to produce a record of regularly gridded global atmospheric variables 
at sub-daily timescales and $2.5^{\circ}$ spatial resolution for the years 1948-present. With this time range, it is the only reanalysis product available that covers the entirety of the Sahelian rainfall shift in the late 1960s-early 1970s (since the ERA-40 Reanalysis (Uppala et al. 2005) only begins in 1957, it misses a large portion of the significantly wet early 1900s). However, we choose to limit our study on the moisture budget of the Sahel to the model output, because previous work (Poccard et al. 2000; Kintner et al. 2004) has shown that the NCEP/NCAR Reanalysis precipitation field over Africa may have spurious trends. Our findings in Sect. 3 highlight the potential shortcomings in using the dataset for this kind of analysis and are further discussed in the "Appendix".

\subsection{Methods}

\subsubsection{Filtering of data}

In order to isolate the decadal signal of precipitation variability, we use a 10-year running mean filter applied to the precipitation and SST data. Due to this technique, the last $\mathrm{n}-1$ data points are eliminated and the running segments are 1901-1910, 1902-1911, and so on until 1990-1999, thus spanning the duration of the twentieth century. In some cases, the filter is not applied to show a baseline for the climatology and standard deviation of precipitation in the region; this is clearly indicated.

\subsubsection{Maximum covariance analysis}

In order to determine the dominant modes of covariability between global ocean surface temperatures and rainfall in the Sahel, Maximum Covariance Analysis (MCA) is used (Bretherton et al. 1992). This technique applies a Singular Value Decomposition (SVD) procedure to the covariance matrix of normalized precipitation and SST anomalies. Filtered data for the MCA are linearly detrended in time followed by normalization of each of the related variables (SST and precipitation) by their spatially averaged variance. For computation reasons, gridded precipitation data are interpolated to a $2^{\circ}$ latitude by longitude grid and a $2^{\circ}$ latitude by $3^{\circ}$ longitude grid for SST before computing the SVD. When the MCA is completed for the model data, it is on the ensemble-averaged precipitation.

\subsubsection{Atmospheric moisture budget}

According to Brubaker et al. (1993), on timescales $>10$ days (i.e. seasonal), precipitation, evaporation, and net moisture transport into or out of an atmospheric column balance (i.e. the time tendency and storage can be neglected). This can be depicted mathematically through the atmospheric moisture budget equation, expressed as:

$\rho_{w} g(P-E)=-\nabla \cdot \int_{0}^{p_{s}} q \boldsymbol{V} d p$.

In this equation, the difference between precipitation $(P)$ and evaporation $(E)$ (converted to $\mathrm{mm} /$ day for this work) is equal to the convergence of the column integrated moisture flux ( $q \boldsymbol{V}$, where $q$ is the specific humidity and $\boldsymbol{V}$ is the horizontal wind vector). $P-E$ is scaled by the density of water $\left(\rho_{w}\right)$ and gravitational acceleration $(g)$. The convergence of the moisture flux can be understood as the net amount of vertically integrated water vapor transport that is present in the atmospheric column.

After taking the time mean on both sides of Eq. 1, the columnar moisture flux convergence can be separated into changes in the moisture convergence due to the monthly mean circulation and changes due to convergence of moisture by intra-monthly transient eddies (Trenberth and Guillemot 1995; Seager et al. 2010), following Seager and Henderson (2013). First, we rewrite the steady state moisture budget in pressure coordinates from Eq. 1 as a summation over the K model pressure levels:

$\rho_{w} g(P-E)=-\nabla \cdot \sum_{k=1}^{K}\left(q_{k} \boldsymbol{V}_{k} d p_{k}\right)$.

(Note that in this study, the vertical integration is carried out on the model's native hybrid-sigma pressure grid in order to achieve more accurate results). We then take the JAS seasonal mean, and get:

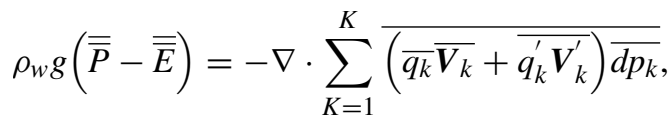

where overbars correspond to the monthly means, primes denote departures from monthly means, and double overbars denote climatological monthly means. The first term on the right-hand side of Eq. 3 represents convergence by the mean flow, while the second term on the right-hand side represents convergence by submonthly transient eddies. Finally, by bringing the divergence operator inside the summation in Eq. 3, the convergence by the mean flow can be further subdivided into two terms:

$$
\begin{aligned}
& \rho_{w} g(\overline{\bar{P}}-\overline{\bar{E}})=-\left[\sum_{K=1}^{K} \overline{\overline{\left(\overline{q_{k}} \nabla \cdot \overline{\boldsymbol{V}_{k}}+\overline{\boldsymbol{V}_{k}} \cdot \nabla \overline{q_{k}}\right) \overline{d p_{k}}}+\nabla \cdot \sum_{K=1}^{K} \overline{\overline{q_{k}^{\prime}}} \overline{\boldsymbol{V}_{k}^{\prime}} \overline{d p_{k}}}\right] \\
& -\overline{\overline{q_{s} \boldsymbol{V}_{s} \nabla p_{s}}}
\end{aligned}
$$

In Eq. 4, the first term on the right-hand side represents the contribution due to mean mass convergence, while the 
second term on the right-hand side represents the contribution due to mean flow moisture advection. Because we moved the divergence operator inside the summation, there is a surface term that results, but this term is generally small in comparison to the others and mainly associated with orographic features. Thus it is neglected for the remainder of this work. For a more detailed description of the moisture budget breakdown and associated errors, the reader is referred to Seager and Henderson (2013). The climatologic and anomalous terms for the moisture budget are computed separately for each model run and later averaged across ensemble members.

\section{Comparison among observations, NCEP/NCAR Reanalysis, and model performance}

Figure 1 provides a visual summary of decadal (10-year running mean) precipitation variability throughout the twentieth century. The detrended average JAS precipitation

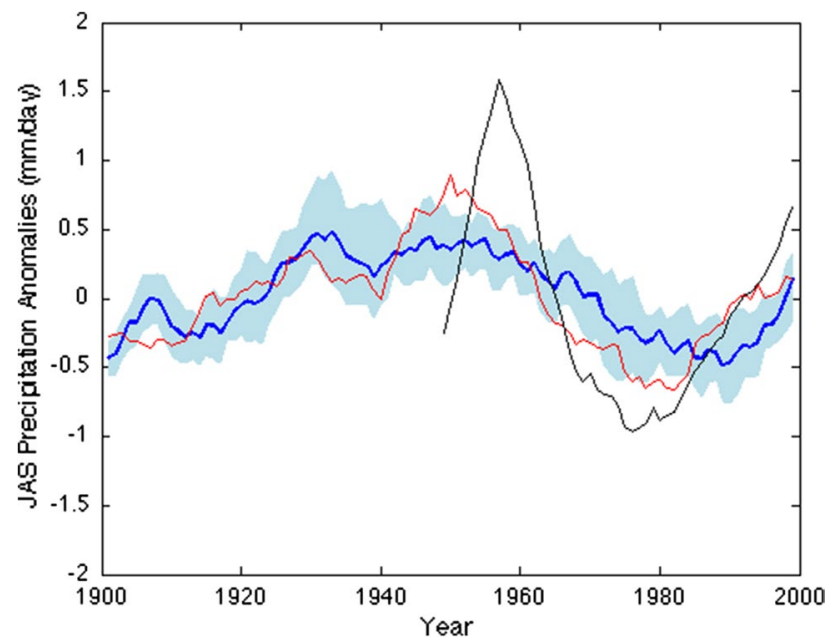

Fig. 1 JAS precipitation anomalies ( $\mathrm{mm} /$ day) for the UEA observations (red line), NCEP/NCAR Reanalysis (black line), and CAM4 model ensemble mean (dark blue line). Light blue shading indicates the 5 th to 95 th percentile of the model runs anomaly ( $\mathrm{mm} /$ day) averaged over the Sahel domain is compared in observations (red line), the NCEP/NCAR Reanalysis (black line) and the model ensemble mean (dark blue line). The light blue shading represents the spread of model values between all ensemble members by showing their 5 th and 95th percentile seasonal values. A few points are clear from this figure. In the observations, there is a shift in the rainfall anomalies from mostly positive prior to the mid1960s to mostly negative afterwards. The model ensemble mean also captures this signal, with dampened variability due in part to the use of the ensemble averaging. The model ensemble spread captures the majority of the variability seen in the observations. The correlation between the decadal UEA observations and the CAM4 ensemble mean is 0.7715 , significant at $\alpha=0.05$. Although there is even stronger correlation among the UEA observations and the NCEP/NCAR Reanalysis $(r=0.8040)$, there are a few concerning points with the use of this dataset. First, the NCEP/NCAR Reanalysis shows a huge drop-off in precipitation that is well outside of that which was observed. Furthermore, later in the century the Reanalysis is much too dry compared to the observations and model, and then it largely overestimates the rainfall anomalies starting around 1995.

In so far as the climatology is concerned, it may be appropriate to use the NCEP/NCAR Reanalysis over the Sahel for a sufficiently long period of time. Figure 2 shows the JAS precipitation climatology ( $\mathrm{mm} /$ day) calculated for the time period common to all datasets (1949-2008) using the unfiltered UEA observations, NCEP/NCAR Reanalysis, and the CAM4 ensemble-averaged, model generated precipitation. Each of the plots shows the coherent band of rainfall observed over the Sahel, with relative maximum in precipitation over the Guinea Coast. Weaknesses of the model include a tendency to rain too much over the Red Sea and the Arabian Peninsula, and a slight western bias of the rainfall distribution. Overall, both NCEP/NCAR and the CAM4 model capture the major features of the Sahelian rainfall climatology during the monsoon months. However, when we study the variability in the three datasets,
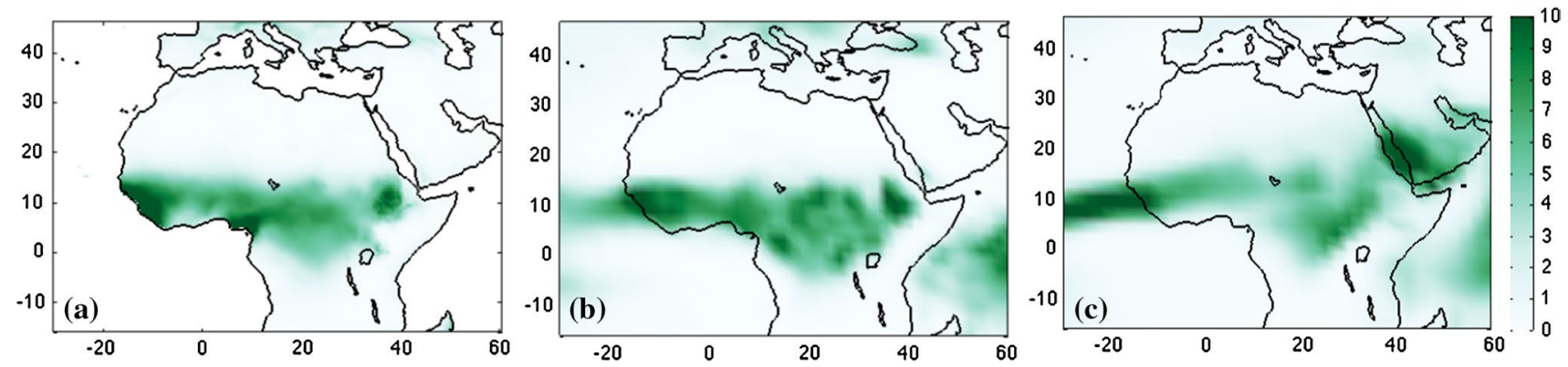

Fig. 2 JAS precipitation climatology (mm/day) for the time period common to all three datasets (1949-2008) for a UEA, b NCEP/NCAR and c CAM4 ensemble average 

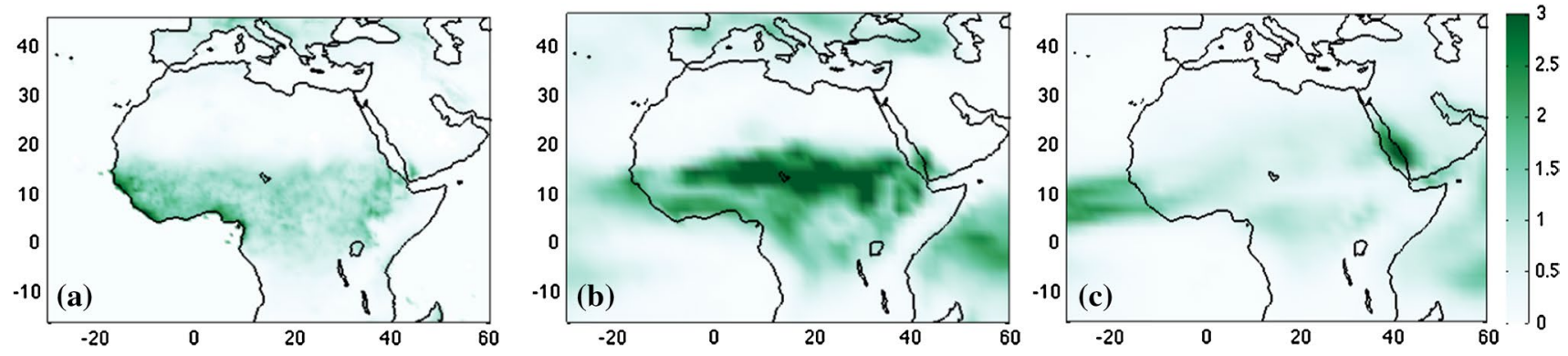

Fig. 3 JAS precipitation root mean square anomaly (mm/day) for the time period common to all three datasets (1949-2008) for a UEA, b NCEP/NCAR and $\mathbf{c}$ CAM4 ensemble average

new insight emerges. Figure 3 shows the unfiltered average JAS precipitation root mean square anomaly $(\mathrm{mm} /$ day) for 1949-2008. It is clear to see from Fig. 3 that while the UEA observations (Fig. 3a) and the CAM4 model (Fig. 3c) generated precipitation fields show similar amounts in their ranges of rainfall variability, the NCEP/NCAR Reanalysis precipitation product (Fig. 3b) greatly overestimates the variability over the Sahel. The variability in the Reanalysis is almost twice as large as the other two in the Sahelian latitude band $\left(10^{\circ}-18^{\circ} \mathrm{N}\right)$.

The above findings are consistent with previous studies questioning the validity of the NCEP/NCAR precipitation fields over Africa. Poccard et al. (2000) show that between the end of the 1950s and the early 1960s, NCEP/NCAR rainfall amounts over the African continent are overestimated by as much as $15-30 \%$ of the observed annual total in some places. While it is known that a true shift in the precipitation regime occurred during this time, using split moving-windows dissimilarity analysis, they showed that the transition in the observations is smaller and much more gradual, while the NCEP/NCAR Reanalysis shift is artificial, due to the change in data availability that occurred around that time. According to the authors, this could have impacted the fields that are model generated, such as precipitation and it is clear from the above analysis that both the magnitude and variability of the rainfall averaged over the Sahel suffers from these errors.

Because the precipitation data is generated by a numerical model and is not directly observed, it is generally expected that precipitation shows larger discrepancies than other fields such as wind or temperature (Janowiak et al. 1998). Given this understanding, others have suggested manually computing the precipitation field using the moisture budget equation applied to the model dynamical fields and the model evaporation (see Sect. 2 above), expecting better results. However, according to Kintner et al. (2004), because in the Tropics the reanalysis precipitation is tightly connected to the dynamical fields the errors are not separable and one cannot expect good results from moisture budget calculations. Indeed, their study found that similar unrealistic shifts in the divergent circulation occur in the tropics consistent with the spurious precipitation shift, and do not correspond with other independent precipitation analyses. We see the same spurious shifts in many of these other atmospheric variables (i.e. evaporation, specific humidity, and horizontal wind speed) when spatially averaged over the Sahel and plotted in time (see "Appendix"), and therefore focus our moisture budget work on modelderived data.

\section{SST teleconnections in the CAM4 model}

The results of our MCA analysis applied to the decadal almost global SST field and African precipitation are shown in Fig. 4. Figure 4a, b show the regression of the SST field (for observations and model, respectively) on the SST time series derived from the MCA (displayed in Fig. 4e, f). The two figures are largely identical as the model is forced by the observed SST. The pattern of SST anomalies seen in these figures is consistent with the ocean areas displaying significant decadal SST anomalies as seen in Fig. 5. Here we isolated areas of the global ocean basins that exhibit strong decadal variability, by applying an F-test to the ratio of SST (i.e. the decadal signal) and the interannual component of the SST variations (calculated as the difference between the total SST anomaly field and its 10-year running mean). The areas of the ocean where the F-test indicates significance ( $\alpha=0.2$, and $\mathrm{F}$ is $\geq 1.06$ ), or equivalently where the decadal variability is significantly different from the interannual component, are shaded. From this plot, we can see that portions of the Indian Ocean and equatorial Atlantic exhibit larger variability on decadal timescales than interannual. It is in these same areas where variability is large in Fig. 4a, b, thus lending confidence in the MCA results.

The summertime spatial patterns of precipitation anomalies that covary with the SST fields (Fig. 4a, b) are shown in Fig. $4 c, d$ for observed and modeled precipitation, respectively. The sign of the anomalies shown in these figures 

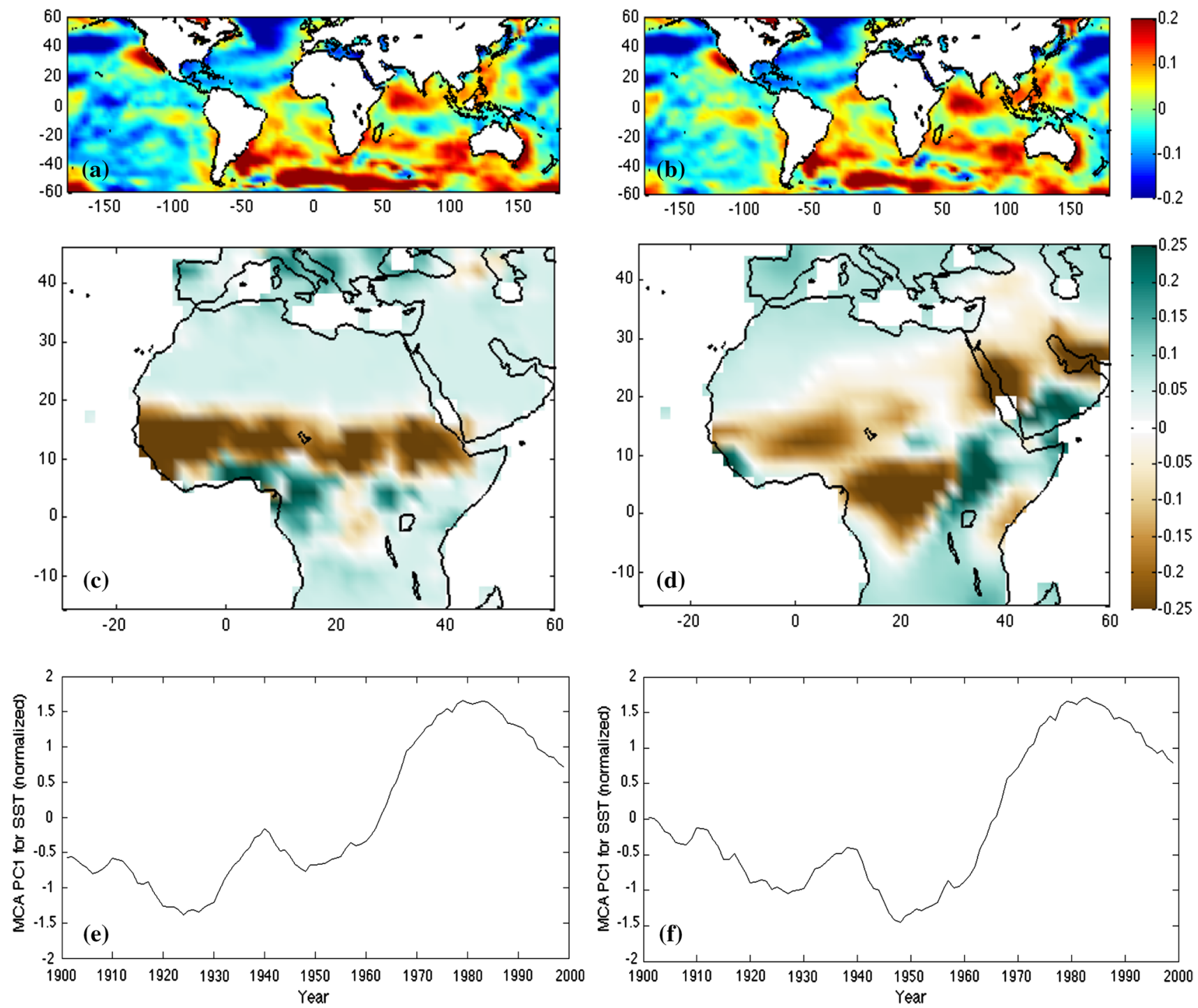

Fig. 4 MCA for observations (left panels) and model (right panels). $\mathbf{a}$ and $\mathbf{b}$ Regression of SST anomalies on the SST Mode 1 (normalized) time series $(\mathbf{e}, \mathbf{f})$. $\mathbf{c}$ and $\mathbf{d}$ Regression of precipitation anomalies

(average JAS in mm/day) on the Mode 1 SST time series. The correlation between the two time series ( $\mathbf{e}$ and $\mathbf{f}$ ) is 0.9240

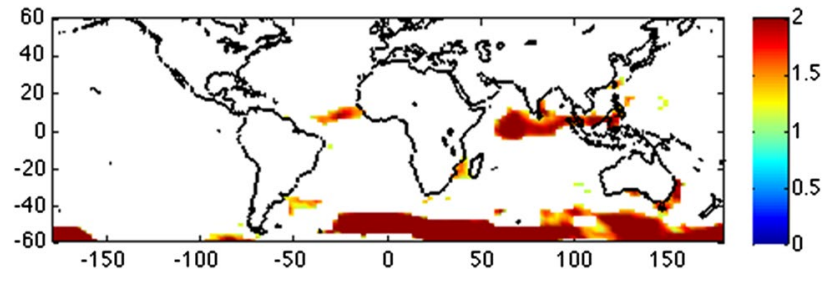

Fig. 5 Results of the F-test for equal variances. Shading indicates significance at $\alpha=0.2$

is set to correspond to the drought phase of the Sahel. We see similar results for both the observations (Fig. 4a, c, e) and the model generated (Fig. 4b, d, f) data, which gives us confidence in using the model for further work. Figure 4a, $\mathrm{b}$ show the regression of the SST data on the indices from Fig. $4 \mathrm{e}, \mathrm{f}$ (respectively). It is clear that in both observations and model, the dominant mode of SST-forcing on decadal timescales that is associated with drying in the Sahel is the meridional temperature gradient in the Atlantic Ocean (relatively cool Northern Atlantic and relatively warm Southern Atlantic), along with warm Indian Ocean SSTs, corroborating previous findings (Giannini et al. 2003; Bader and Latif 2003; Lu 2009; Hoerling et al. 2006). Panels 4c and $d$ then show the spatial pattern of precipitation anomalies ( $\mathrm{mm} /$ day) regressed onto the SST Mode 1 time series. In both model and observations, we see that the Atlantic SST dipole pattern and the Indian Ocean warming are associated 
with a decrease in precipitation over the Sahel region of Africa. The model similarity to observations confirms that the change in SST is forcing the change in precipitation. The regression coefficients are of similar magnitude and agree well spatially. In both cases the precipitation anomalies associated with the SST patterns described above are characterized by drying throughout the extent of the Sahel band, and relatively wet conditions in equatorial and Southern Africa. There is a tendency of the model to dry too much over equatorial Africa as compared to the observations, as well as over the Arabian Peninsula, where model summer rains are more intense and spread more widely than in observations (Fig. 2). The model also does not capture the concomitant wetting over the Gulf of Guinea that is seen in the observations and fails to simulate the extent of the coherent dry band through Eastern Africa (Ethiopia), where drying occurs in observations. Despite these inconsistencies, the overall characteristics of a dry Sahel are well represented by the model. Finally, the SST normalized time series for both observations and model (Fig. 4e, f) are very similar, with a correlation coefficient of 0.9240 , significant at $\alpha=0.05$. The total variance explained for the precipitation pattern by the SST time series is similar in observations $(42 \%)$ and model $(45 \%)$.

\section{Model moisture budget climatology}

Having validated the performance of the CAM4 model in representing important relationships between SSTs and Sahel precipitation, and pointing to the lack of accurate, available observations that span the entire twentieth century, we now focus on analysis of the model generated variables only. Figure 6 details the spatial distribution of the unfiltered average JAS model climatology (1901-2008) for precipitation (Fig. 6a), evaporation (Fig. 6b), and their difference (P-E, Fig. 6c). Also shown are the total moisture flux convergence (Fig. 6d), moisture convergence by the mean flow (Fig. 6e), and moisture convergence by the transient flow (Fig. 6f). The contribution of mean flow mass convergence (Fig. 6g) and mean flow moisture advection (Fig. 6h) to the total mean flow moisture flux convergence are also shown. Here all variables are expressed in $\mathrm{mm} /$ day and convergence (divergence) is indicated by the green (brown) shading. By studying the variables from the moisture budget separately, these plots provide interpretation for the mechanisms governing average precipitation and its variability that occurs over Africa and particularly, the Sahel. The climatological precipitation field (Fig. 6a) shows a coherent band of rainfall which coincides with the northern intrusion of the West African Monsoon, and appears to be centered around $10^{\circ}-12^{\circ} \mathrm{N}$. The evaporation field (Fig. 6b) largely resembles the precipitation field, as to be expected, since the moisture available for evaporation over land largely comes from antecedent precipitation. The largest areas of evaporation occur over the oceans, where there is a relatively infinite supply of moisture. When the difference between the two fields (Fig. 6c) is taken, we clearly see the delineation between areas with positive P-E (i.e. areas where precipitation exceeds evaporation) and those with negative P-E (i.e. areas where evaporation exceeds precipitation). The climatology for the monsoon months shows excess $\mathrm{P}$ over $\mathrm{E}$ throughout the Sahel, with a relative maximum on the Western Coast extending into the Atlantic Ocean. In Fig. 6c, positive P-E (net moisture) can also be seen clearly seen over the Indian Ocean.

Based on the moisture budget equation, P-E (Fig. 6c) equals the column integrated total moisture flux convergence (Fig. 6d). For the most part, we can see rough agreement between these two terms in our model output. The convergence band in Fig. $6 \mathrm{~d}$ tends to not be as coherent in space throughout the Sahel, and thus is a bit noisier than P-E [for discussion of the source of errors in calculating a moisture budget from model data see Seager and Henderson (2013)]. Also, when the total moisture flux convergence (Fig. 6d) is calculated, there tends to be too much convergence (and consistently positive P-E) over the Sahara desert, an area where it hardly rains in nature, thus reflecting a model bias. When we break the total moisture flux convergence into convergence due to the mean flow (Fig. 6e) and convergence due to transient, subseasonal eddies (Fig. 6f), we can clearly see that in terms of the climatology, the total moisture flux convergence and consequently the precipitation field are dominated by convergence due to the mean flow itself. In some areas, such as over Senegal and southwestern Mali, the transients tend to work in opposition to the mean flow and produce divergence of the moisture flux, but overall in a climatologic sense, the transients also wet the Sahel by converging air over the region, although with a much smaller magnitude than the mean component.

When we further divide the convergence by the mean flow into a part due to mass convergence (Fig. $6 \mathrm{~g}$ ) and a part due to the advection of specific humidity gradients (Fig. 6h), we see that the converging mass dominates over humidity advection. The magnitude of the converging air is larger and follows the same tendency as the convergence by the mean flow, which is to converge air over the extent of the Sahel, thus producing wetting. On the other hand, the advection of specific humidity gradients tends to dry the Sahel in a climatologic sense. It does this both by carrying dry air from the northern Sahara into the region, as well as by driving moisture out of the region and towards the Atlantic Ocean. The advection of moisture out of the region is not sufficient to deplete the area of moisture however, and overall convergence by the mean flow still wins out in 
(a)

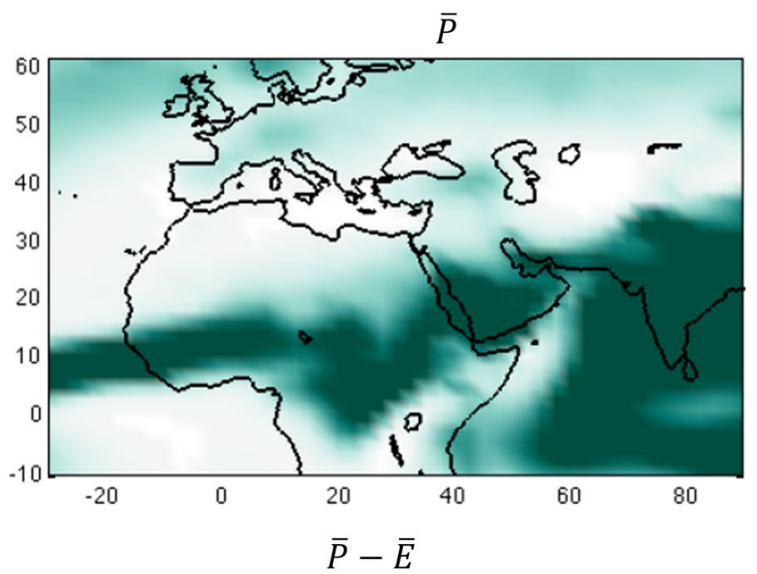

(c)

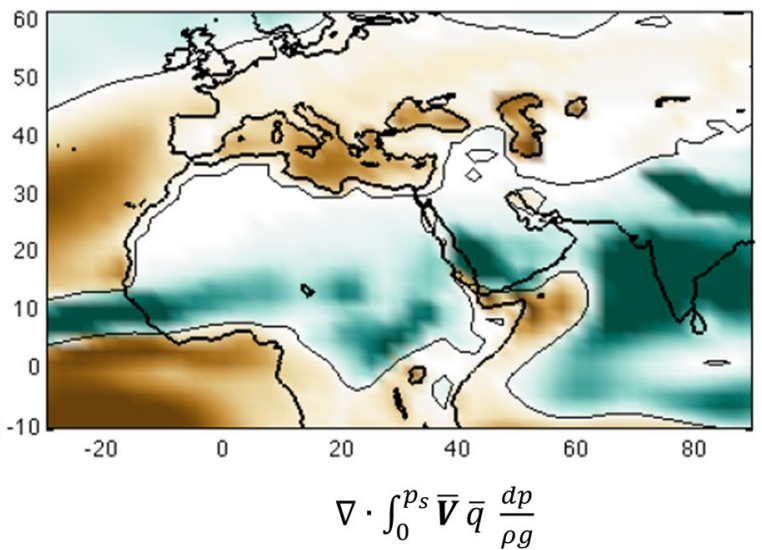

(e)

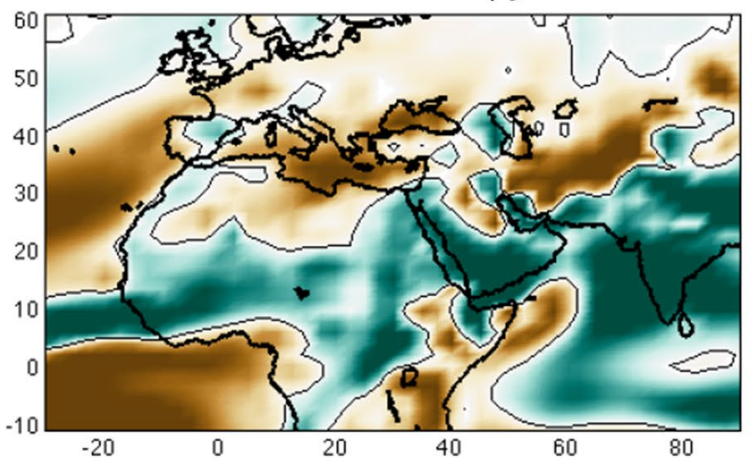

$\int_{0}^{p_{s}}(\bar{q} \nabla \cdot \overline{\boldsymbol{V}}) \frac{d p}{\rho g}$

(g)

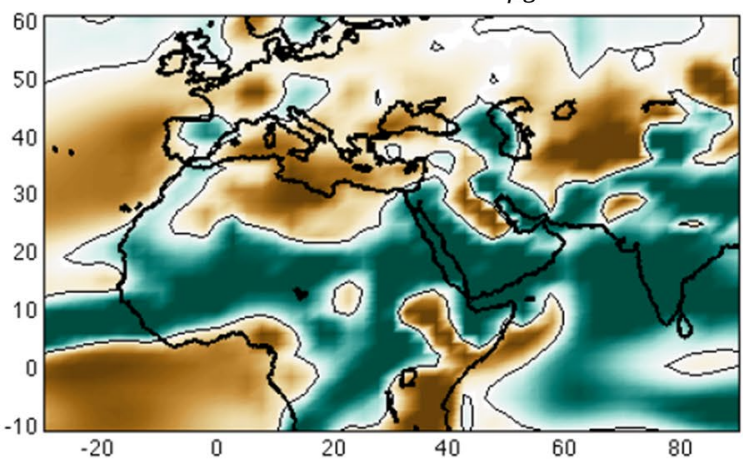

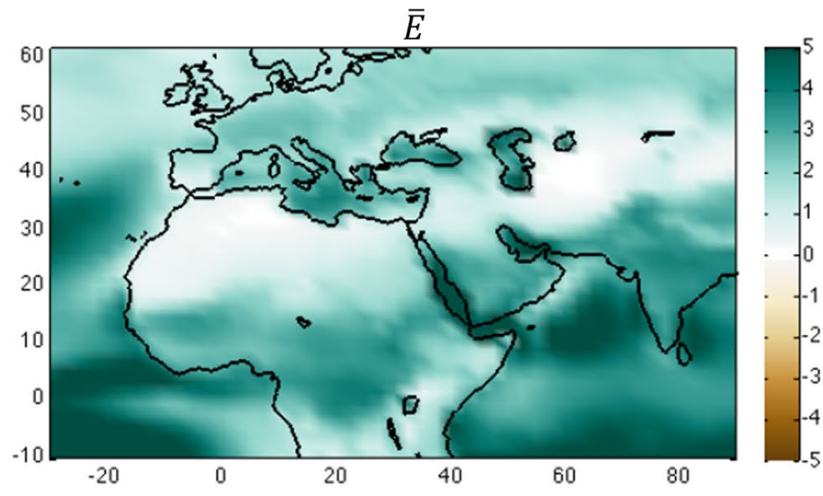

(b)

$\nabla \cdot \int_{0}^{p_{s}} \overline{\boldsymbol{V} q} \frac{d p}{\rho g}$

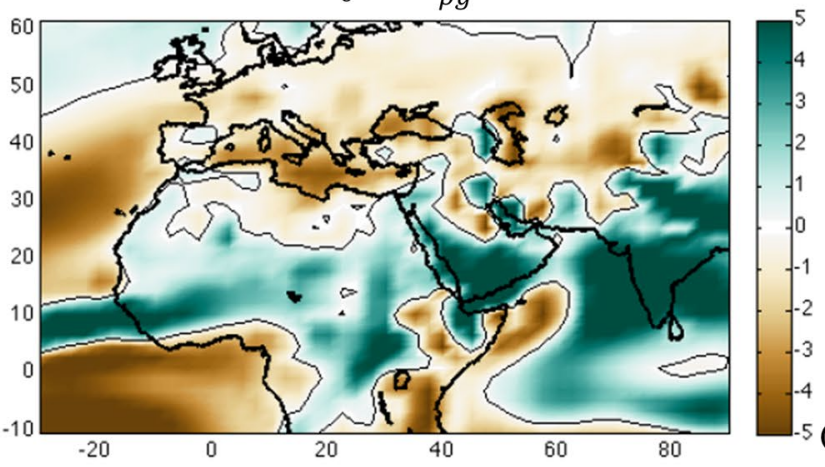

(d)

$\nabla \cdot \int_{0}^{p_{s}} \overline{\boldsymbol{V}^{\prime} q^{\prime}} \frac{d p}{\rho g}$

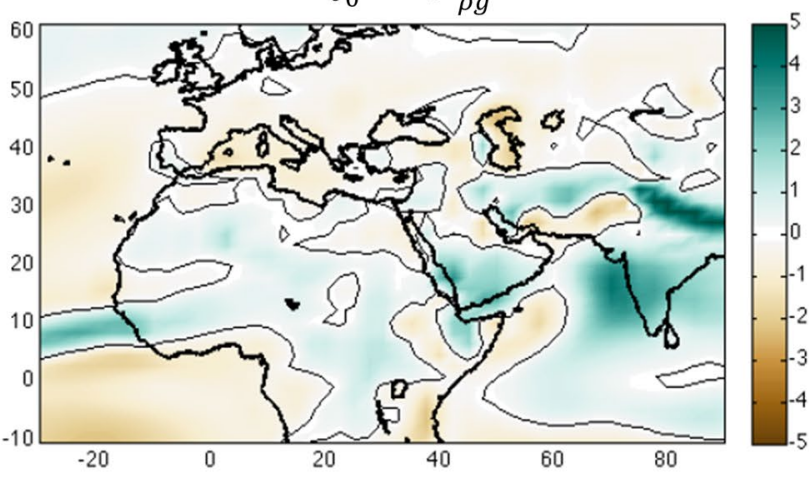

$\int_{0}^{p_{s}}(\overline{\boldsymbol{V}} \cdot \nabla \bar{q}) \frac{d p}{\rho g}$

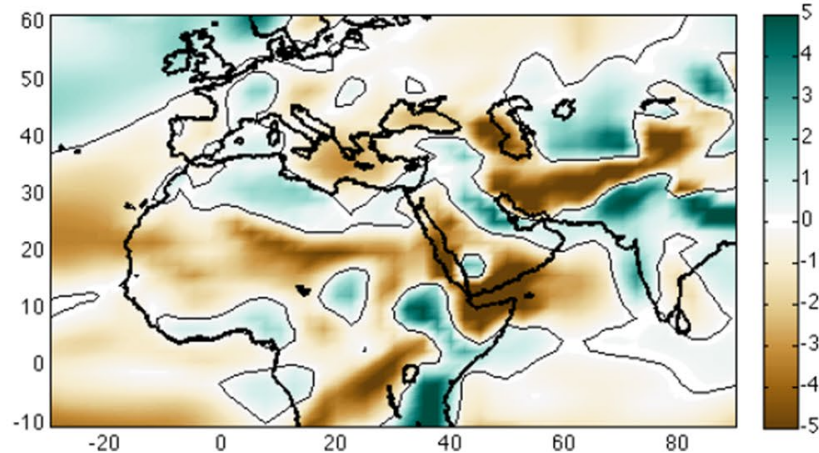

(h)
Fig. 6 JAS model climatology for a precipitation, b evaporation, c $\mathrm{P}-\mathrm{E}$, $\mathbf{d}$ total moisture flux convergence, $\mathbf{e}$ convergence by the mean flow, $\mathbf{f}$ convergence by the transient flow, $\mathbf{g}$ mass convergence and $\mathbf{h}$ advection of specific humidity. All terms have been converted to $\mathrm{mm} /$ day. Note that convergence is ' + ' or green and divergence is ' - ' or brown. The zero contour is shown in black 
(a)

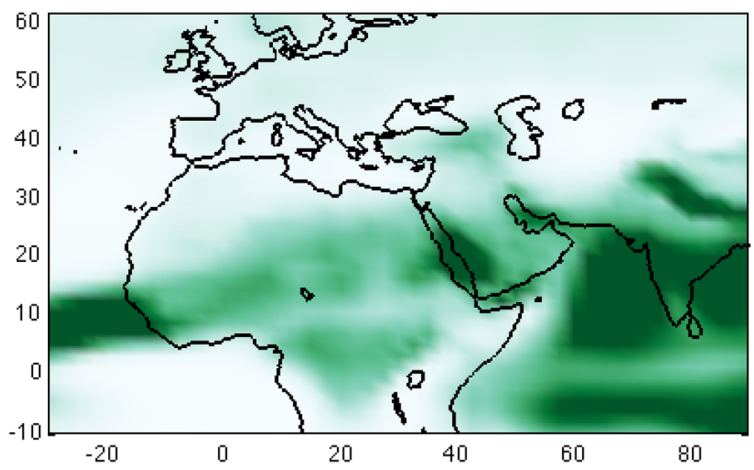

(c)

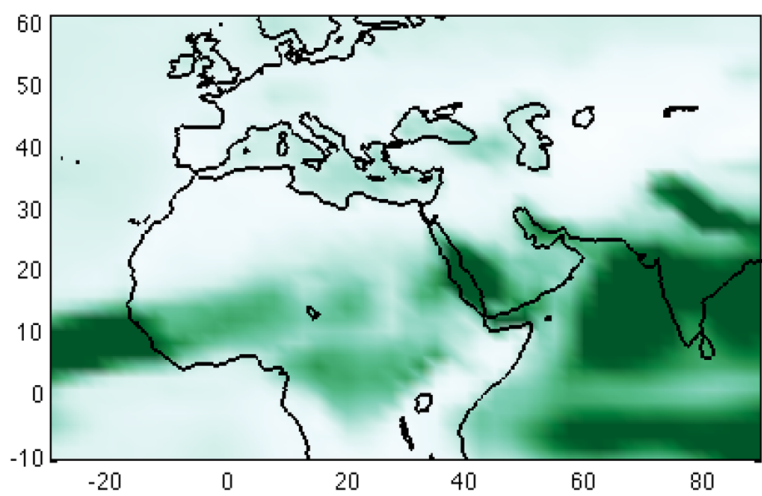

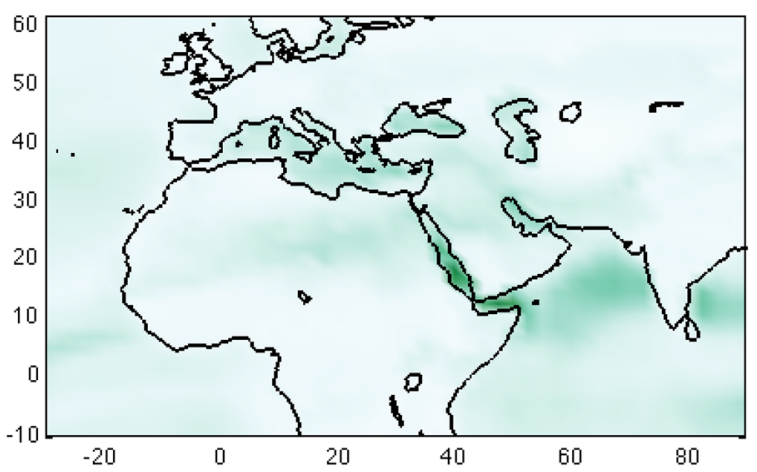

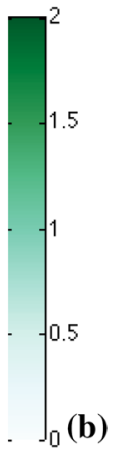

Fig. 7 JAS standard deviation (1901-2008) for a precipitation, b evaporation, c P-E. All terms are in mm/day

the climatology. It is interesting that the patterns of mass convergence and the advection of specific humidity almost precisely work in opposition to one another, even showing weak divergence of the former east of Lake Chad and vice versa for the latter. More about the relationship between these two processes is discussed in Sect. 7.

Figure 7 presents the standard deviation of the precipitation (Fig. 7a), evaporation (Fig. 7b), and P-E (Fig. 7c) in the study area. These standard deviation plots show that the precipitation field (Fig. 7a) varies substantially, while the variability in the evaporation field (Fig. 7b) is damped. This is to be expected as the evaporation over land works as a slave to the precipitation, and is dependent upon it. The observed spatial gradients in net moisture at the surface (i.e. P-E, Fig. 7c) are thus not due to gradients in local evaporation but rather to the strong spatial gradients in precipitation itself.

\section{Moisture budget of decadal variations}

To examine the moisture budget components associated with the hydroclimate changes forced by the decadal SST pattern depicted in Fig. 4b, in Fig. 8 we regress the 1901-1999 moisture budget anomalies ( $\mathrm{mm} /$ day) on the corresponding SST time series (Fig. 4f). This particular phasing of SSTs and precipitation allows us to study variations in the moisture budget that help explain the observed twentieth century drought. The regressions of each of the moisture budget terms are shown in Fig. 8 by the color shading, where green (brown) again corresponds to convergence (divergence). To facilitate comparison, the climatological fields from Fig. 6 are overlain on the panels of Fig. 8 in black contours, with dotted contours for positive values, dashed for negative, and solid for the zero contour. The dominant decadal scale SST pattern shown in Fig. 4b forces drying over much of the African continent, as seen in Fig. 8a. Compared to the climatology, there is a slight southward shift of the rainbelt over the Tropical Atlantic and in the west, which corresponds to the Atlantic Ocean meridional temperature gradient forcing a shift in the location of the Intertropical Convergence Zone (ITCZ). The latitude of maximum precipitation in the west now occurs southward of $10^{\circ} \mathrm{N}$ and over the ocean, which is in contrast to the climatology where this occurs over West Africa centered around approximately $10^{\circ}-15^{\circ} \mathrm{N}$. Due to this drop in precipitation over the northern Sahel, there is a visible decrease in evaporation associated with the SST patterns that occurs over the region of precipitation decrease (Fig. 8b). This is not the case south of about $\sim 15^{\circ} \mathrm{N}$, where evaporation increases slightly. The model output thus suggests that over the northern Sahel evaporation could have further amplified the local drying due to a lack of moisture 
(a)
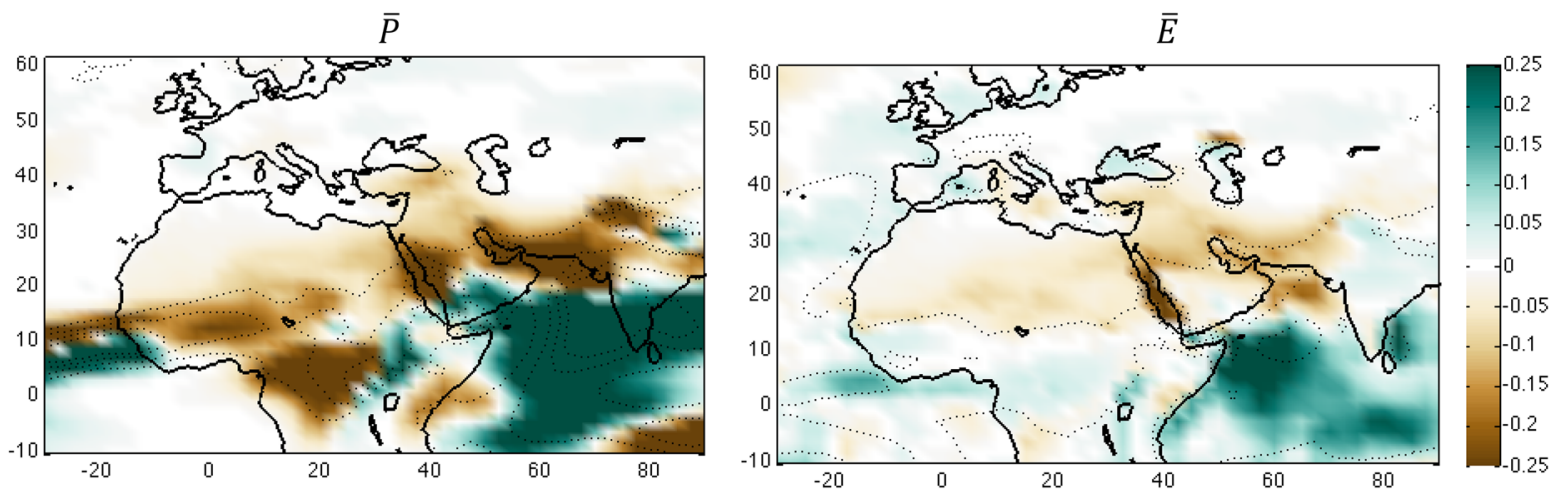

(b)

$\bar{P}-\bar{E}$

(c)

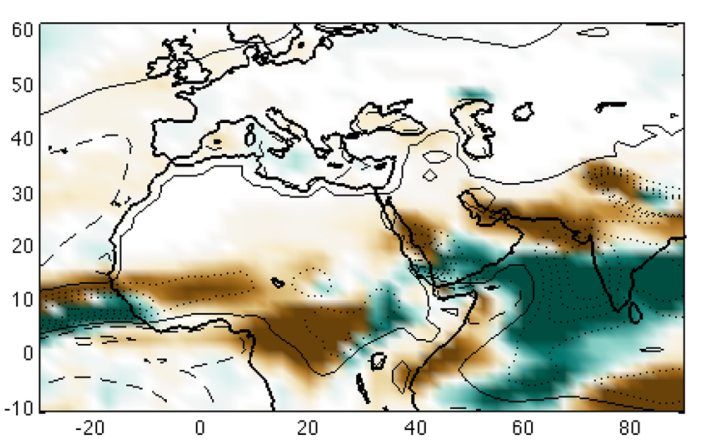

$\nabla \cdot \int_{0}^{p_{s}} \overline{V q} \frac{d p}{\rho g}$

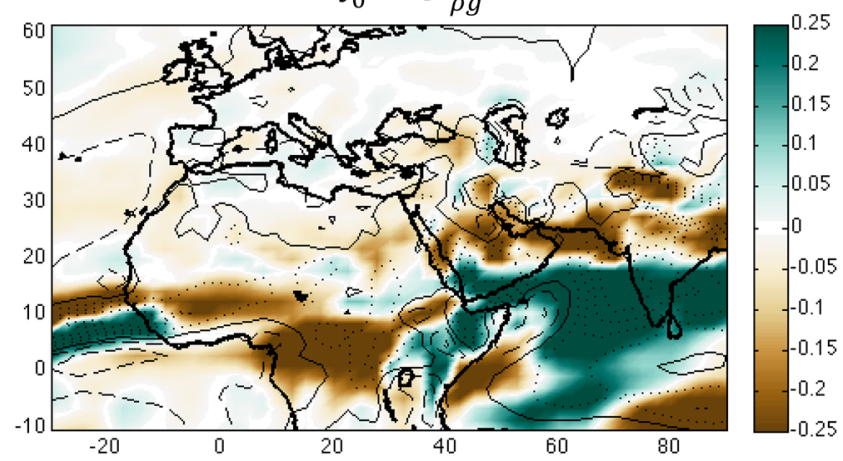

$\nabla \cdot \int_{0}^{p_{s}} \overline{\boldsymbol{V}} \bar{q} \frac{d p}{\rho g}$

(e)

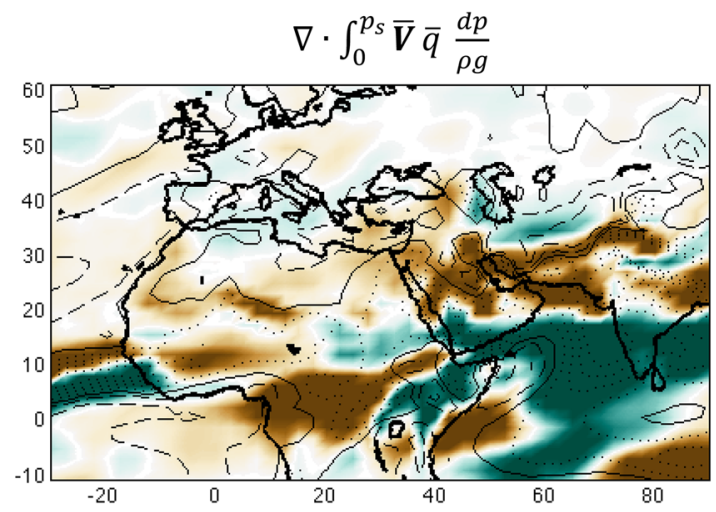

$\nabla \cdot \int_{0}^{p_{s}} \overline{V^{\prime} q^{\prime}} \frac{d p}{\rho g}$

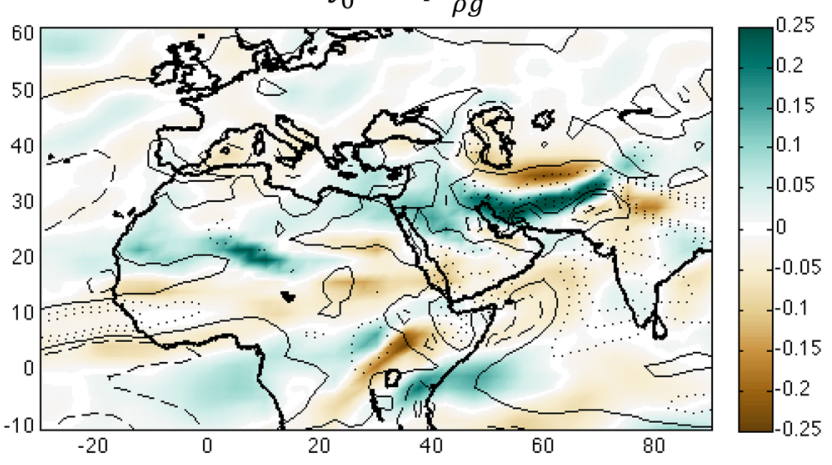

$\int_{0}^{p_{s}}(\bar{q} \nabla \cdot \bar{V}) \frac{d p}{\rho g}$

$\int_{0}^{p_{s}}(\overline{\boldsymbol{V}} \cdot \nabla \bar{q}) \frac{d p}{\rho g}$

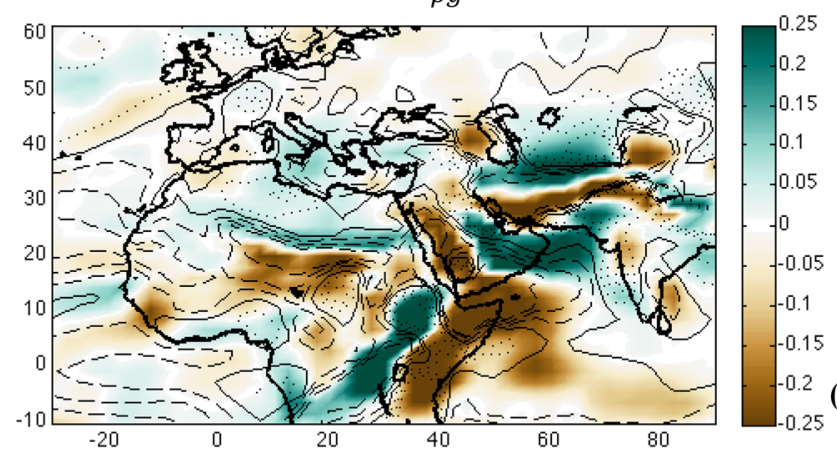

(h)

Fig. 8 Regression of model output JAS anomalies (colors) on the model SST index from Fig. 4 for a precipitation, b evaporation, $\mathbf{c}$ P-E, $\mathbf{d}$ total moisture flux convergence, $\mathbf{e}$ convergence by the mean flow, $\mathbf{f}$ convergence by the transient flow, $\mathbf{g}$ mass convergence and $\mathbf{h}$ advection of specific humidity. All terms have been converted to $\mathrm{mm} /$ day. Contours

show the climatologic values from Fig. 6. Solid black line denotes the 0 contour, dotted lines denote positive contours and dashed lines denote negative contours. The contour interval is from -10 to 10 by $2.5(\mathrm{~mm} /$ day) in all plots except for convergence by the transients (Fig. 8f) and specific humidity advection (Fig. $8 \mathrm{~h}$ ) where it is -3 to 3 by 1 ( $\mathrm{mm} /$ day) 
Fig. 9 Regression of columnintegrated moisture flux vectors on the model SST index from Fig. 4

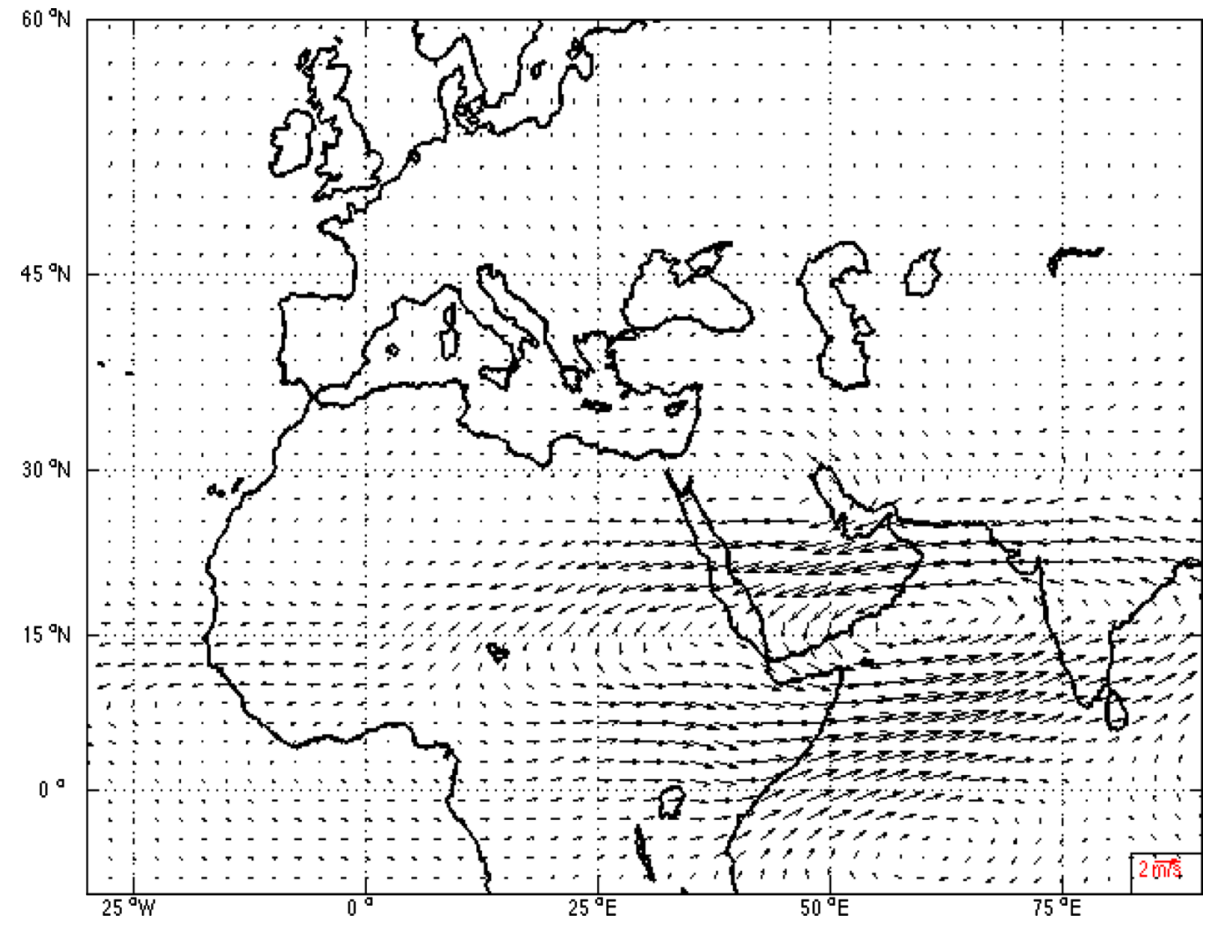

recycling from local rainfall. Not surprisingly, the P-E term (Fig. 8c) largely resembles the precipitation patterns, showing net negative moisture flux where the climatology shows positive (dotted contours). There is a slight bias in the model to continue to show positive P-E along the eastern flanks of the Sahel, roughly corresponding to parts of Chad, Sudan, and Ethiopia.

Besides this area of the Sahel with weak moisture convergence, the total moisture flux term (Fig. 8d) for the rest of the region exhibits moisture divergence associated with the SST phase in Fig. 4d. We also see convergence over the Indian Ocean concomitant with the large-scale divergence in the Sahel noted above. The divergence is dominated by the mean flow (Fig. 8e) and as argued before is part of a Rossby wave response to the convergence over the Indian Ocean (Giannini et al. 2005; Lu 2009; Hagos and Cook 2008). According to Hagos and Cook (2008), the subsiding and diverging air over Central and West Africa produces an anticyclonic circulation in the region, which drives westward transport of moisture away from the continent. This can be seen in the specific humidity advection plot (Fig. 8h) where there exists a negative advection of humidity centered along $\sim 10^{\circ} \mathrm{N}$ and $10^{\circ} \mathrm{W}$.

It is clear once more that the total moisture flux convergence (Fig. 8d) is dominated by the mean flow convergence (Fig. 8e), as the two are nearly identical not only in their climatologies but also in the regression plots. During the phasing of SSTs described above, the transients (Fig. 8f) also contribute to the drying observed through the twentieth century, showing weak divergence patterns over West Africa that extend eastward into the continent. In the case of the western Sahel, the tendency for both the mean flow and transient flow to diverge moisture results in the particularly dry Sahel shown in Fig. 8c, d. It is also the case that the drying by the mean flow term in the west is attributable to both the divergence of air mass (Fig. 8g) and advection of specific humidity (Fig. 8h) there. However as noted previously, in both the P-E (Fig. 8c) and total convergence (Fig. 8d) plots, there is weak convergence in the eastern Sahel, in particular to the east of Lake Chad. This is coming from convergence by the mean (Fig. 8e), specifically from mass convergence (Fig. 8g), whereas the moisture advection term (Fig. 8h) dries the area. It can be seen from a plot of the column-integrated moisture flux vectors (Fig. 9), that there is indeed convergence of the air parcels to the east of Lake Chad. However, these air trajectories are bringing with them dry air from the Sahara desert and Arabian Peninsula. Thus even though the air masses converge (Fig. 8g) along approximately $15^{\circ} \mathrm{N}$, the advection of the dry parcels (Fig. 8h) partially offsets this effect so that in the net, the mean flow (Fig. 8e) shows weak convergence in the eastern Sahel. Over most of the western Sahel both mass divergence and dry air advection contribute to drying. The transients (Fig. 8f) also act to dry the entire region across the African continent.

\section{Moisture budget terms and dynamics in wet and dry periods}

To better understand the hydrological changes in the main rainbelt of the western Sahel, we plot a series 
of pressure-latitude cross sections (averaged over $\left.10^{\circ} \mathrm{E}-10^{\circ} \mathrm{W}\right)$ from the model ensemble mean. Following the arguments made by Hagos and Zhang (2010), the cross sections based on model climatology help to distinguish how the terms operate both in areas where strong latent heating occurs and where it is absent, while the difference between dry and wet periods provides insight into the dynamics of the SST-driven decadal variability.
Figure 10 shows the latitudinal distribution in rainfall amounts in the climatology (Fig. 10a) and the normalized anomalies during the wet and dry years (Fig. 10b). In the latter panel, the rainfall changes over land are largest in the rainbelt maximum region, and decline northward. Figure 11 shows latitude-pressure cross sections of the meridional and vertical wind fields in the climatology and for the dry minus wet years (Fig. 11a, b, respectively). Note that
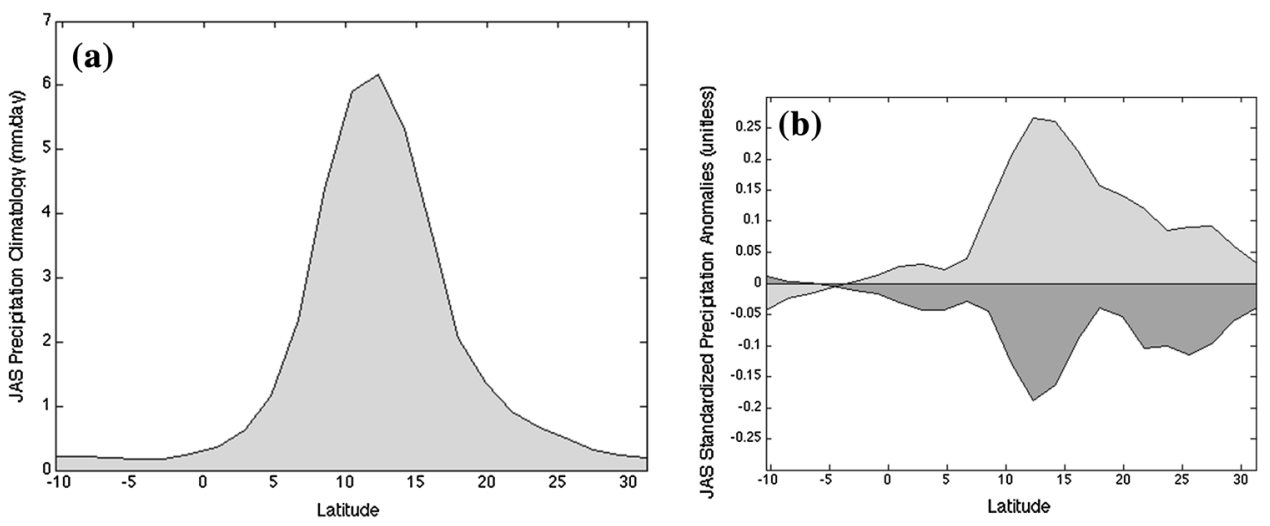

Fig. 10 a JAS model precipitation climatology ( $\mathrm{mm} /$ day) as a function of latitude and $\mathbf{b}$ standardized anomalies (unitless) during the wet period (light grey) and dry period (dark grey)
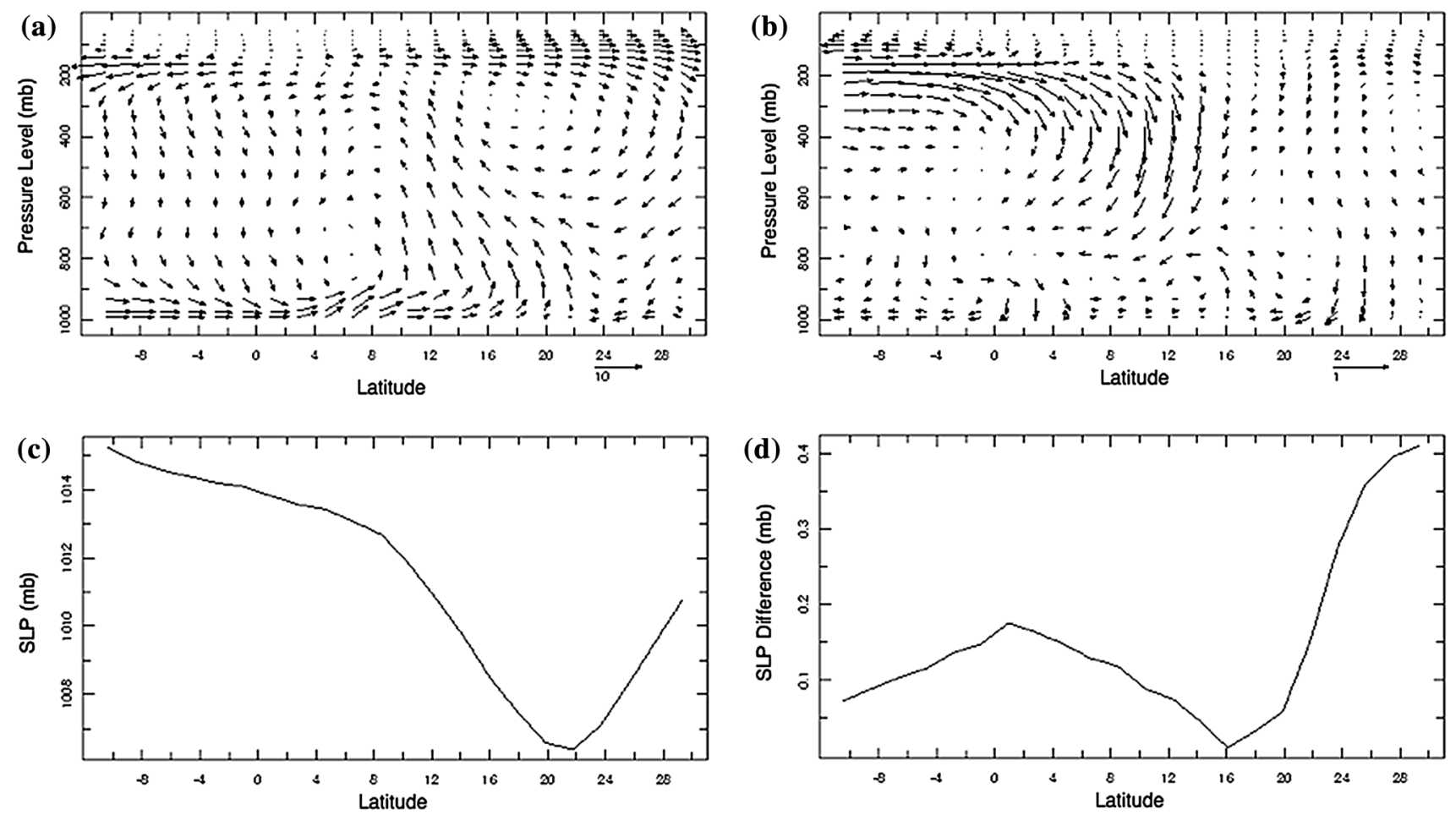

Fig. 11 a and b JAS meridional and vertical velocity (m/s) as a function of latitude and pressure level for a climatology and $\mathbf{b}$ dry-wet years difference. Note that a scaling of 10 has been applied to the ver-

tical velocity component. $\mathbf{c}$ and d JAS sea level pressure (SLP, in mb) as a function of latitude for $\mathbf{c}$ climatology and $\mathbf{d}$ dry-wet years difference 
the vertical velocity has been scaled by a factor of 10 to better display the overturning components of the circulation. According to Hagos and Zhang (2010), the mass circulation in this region is dominated by the divergent wind component and the role of the rotational wind is negligible. Thus the winds depicted in this figure relate closely to the mass divergence and moisture advection discussed below. In the climatology (Fig. 11a), surface southerlies and northerlies converge around $22^{\circ} \mathrm{N}$, where the Saharan heat low is found (Fig. 11c). Over the center of the surface low, the air rises throughout the lower troposphere, below $\sim 600 \mathrm{mb}$. The rising motion associated with the heat low combines with the deep vertical upward flow over the rainfall maximum at $\sim 12^{\circ} \mathrm{N}$. This creates an impression of a shift in the rising column associated with the maximum precipitation region (see also Hagos and Zhang 2010).

The difference plot (Fig. 11b) prominently displays a decrease in the upward flow of air around $12^{\circ} \mathrm{N}$ during the dry period, consistent with the reduction in precipitation (Fig. 10b). Furthermore, anomalous subsidence dominates throughout the troposphere above $\sim 800 \mathrm{mb}$ in the main rainbelt, from about $8^{\circ}-16^{\circ} \mathrm{N}$. Near the surface, changes in the flow are connected with the changes in the intensity of the Saharan heat low seen in Fig. 11d. There is an increased convergence associated with advection of dry air from the north around the heat low center $\left(18^{\circ}-24^{\circ} \mathrm{N}\right)$ into the Sahel. This "filling in" or weakening of the surface low has been previously shown to coincide with less rainfall in the Sahel in model studies (Biasutti et al. 2009). The sea level pressure climatology panel (Fig. 11c) clearly shows the Saharan thermal low at approximately $22^{\circ} \mathrm{N}$. The difference panel shows increasing pressure during the dry period across the land section shown but there is a greater increase in the surface pressure from the center of the heat low northward than to the south, indicating the same weakening of the low as the wind field suggests.

Figure 12 presents latitude pressure cross sections for the model ensemble mean JAS climatology (left column) and dry minus wet years difference (right column). Here the moisture flux convergence and its component terms are shown, revealing consistent behavior with the dynamical interpretations made above. Panels a and $b$ show the total moisture flux convergence. In the climatology, consistent with the heuristic model of the monsoon in Hagos and Zhang (2010), strong near surface divergence over the ocean (south of $\sim 7^{\circ} \mathrm{N}$ ) feeds a broad region of strong nearsurface convergence that stretches from about $10^{\circ}$ to $25^{\circ} \mathrm{N}$. Low tropospheric convergence extends through the precipitation maximum into the relatively dry areas north of about $18^{\circ} \mathrm{N}$ (see Fig. 10a). Consistent with the absence of strong precipitation northwards of $18^{\circ} \mathrm{N}$ there is strong divergence at mid-levels ( $500-800 \mathrm{mb})$, centered on approximately $20^{\circ} \mathrm{N}$ that in the vertical integral balances the convergence at the surface in this same region and caps the shallow convection. Alternatively, a weaker divergence center in the mid-troposphere which is not of sufficient strength to counter the surface convergence, is centered on approximately $10^{\circ} \mathrm{N}$, resulting in a net convergence in the column-i.e., positive $\mathrm{P}-\mathrm{E}$.

In the difference plot (Fig. 12b), stronger divergence prevails above approximately $900 \mathrm{mb}$ throughout the high precipitation latitude band $\left(\sim 10^{\circ}-18^{\circ} \mathrm{N}\right)$ during the dry period compared to the wet period, which is consistent with the reduced rainfall. The behavior near the surface displays a weak reduction of low-level convergence during the dry period south of $\sim 15^{\circ} \mathrm{N}$ and an increase in surface convergence during the dry period between $15^{\circ} \mathrm{N}$ and $20^{\circ} \mathrm{N}$. This increase is confined to the lower troposphere and appears more than compensated by the overlaying layer of mid to upper level divergence, thus explaining the overall drying in the region. Evidence from the wind field (Fig. 11b) also suggests that the anomalous moisture convergence is related to mass convergence as seen in Fig. 12d.

Panels $12 \mathrm{c}$ and e show the contribution of mass convergence and humidity advection to the total moisture flux convergence in the climatology. It is clear from both panels that the climatological convergence of air masses plays the dominant role in the total, near-surface moisture flux convergence. Strong surface convergence (Fig. 12c) extends further northwards than the latitude of maximum precipitation (Fig. 10a). In the mid-troposphere over the rainbelt, it is mass flux divergence (Fig. 12c) that is primarily responsible for only partially balancing the nearsurface moisture flux convergence in the atmospheric column (Fig. 12a). North of $15^{\circ} \mathrm{N}$, the strong center of moisture flux divergence at mid-levels is largely due to humidity advection (Fig. 12e). This is associated with dry air advection from the north (Fig. 11a). There is however a secondary contribution from mass flux divergence centered over the Saharan heat low (Fig. 12c). Thus, consistent with expectations and with the heuristic model of Hagos and Zhang (2010), the behavior in the precipitating versus non-precipitating regions differ; whereas net column mass convergence is the dominant term in the rainbelt, the major factor in determining the northward extent of the precipitation band is the advection of specific humidity or the circulation bringing dry air from the north into the Sahel.

Panels $d$ and $f$ show the moisture balance components for the dry minus wet years, respectively. Note that overall changes in mass flux convergence (Fig. 12d) play a dominant role in the total moisture flux convergence changes (Fig. 12b). The only region where the contribution from humidity advection stands out is just north of the rainfall maximum, centered at $15^{\circ} \mathrm{N}$, where advection increases moisture divergence centered at $\sim 800 \mathrm{mb}$; increased 

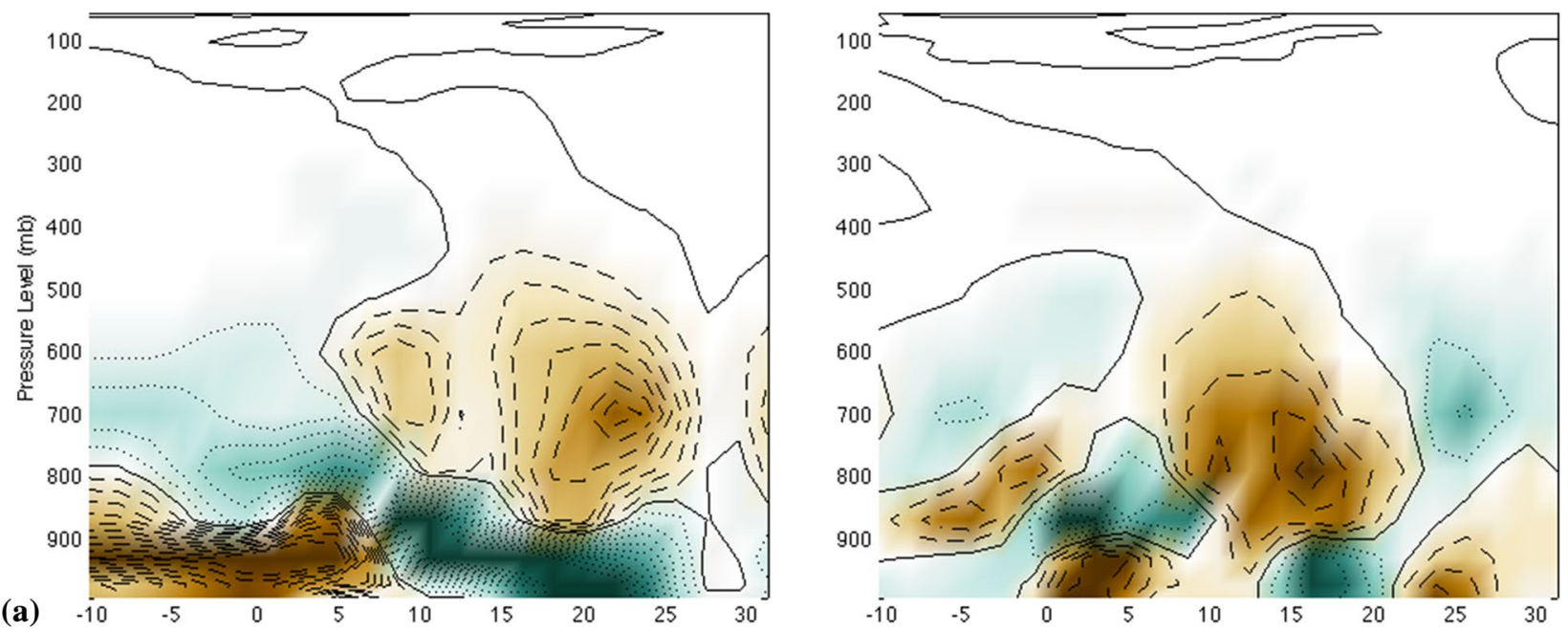

(b)
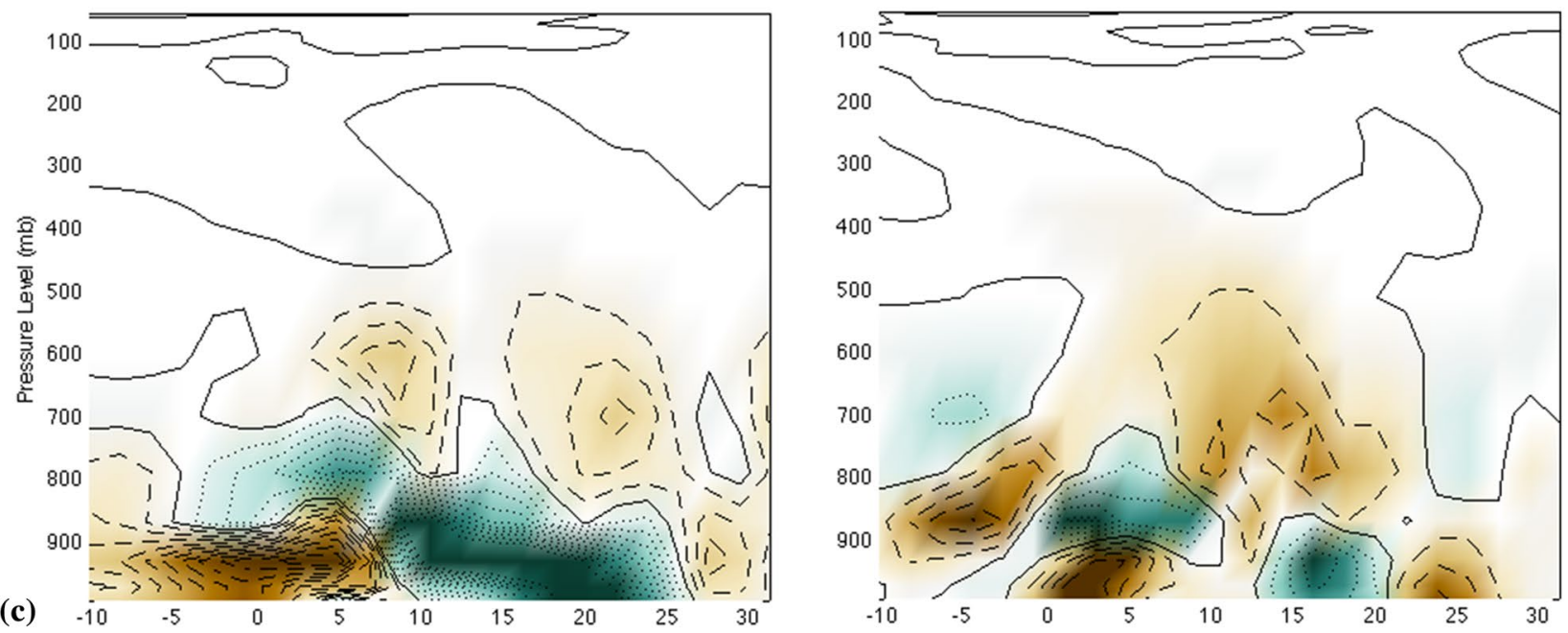

(d)

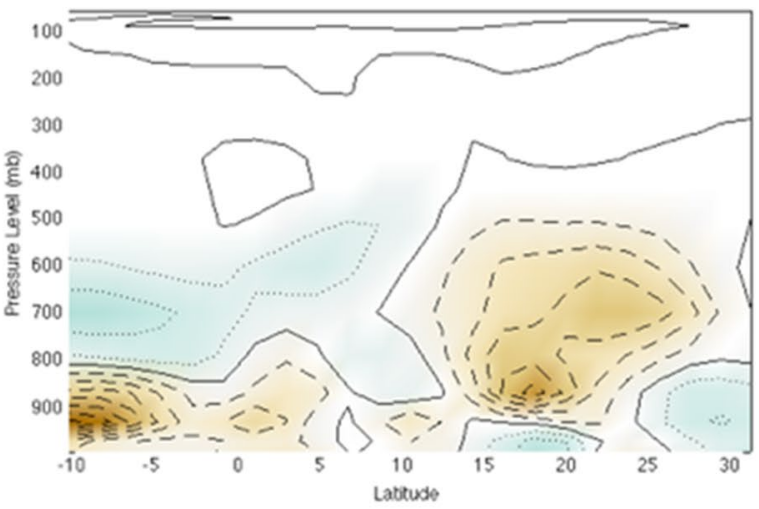

(e)
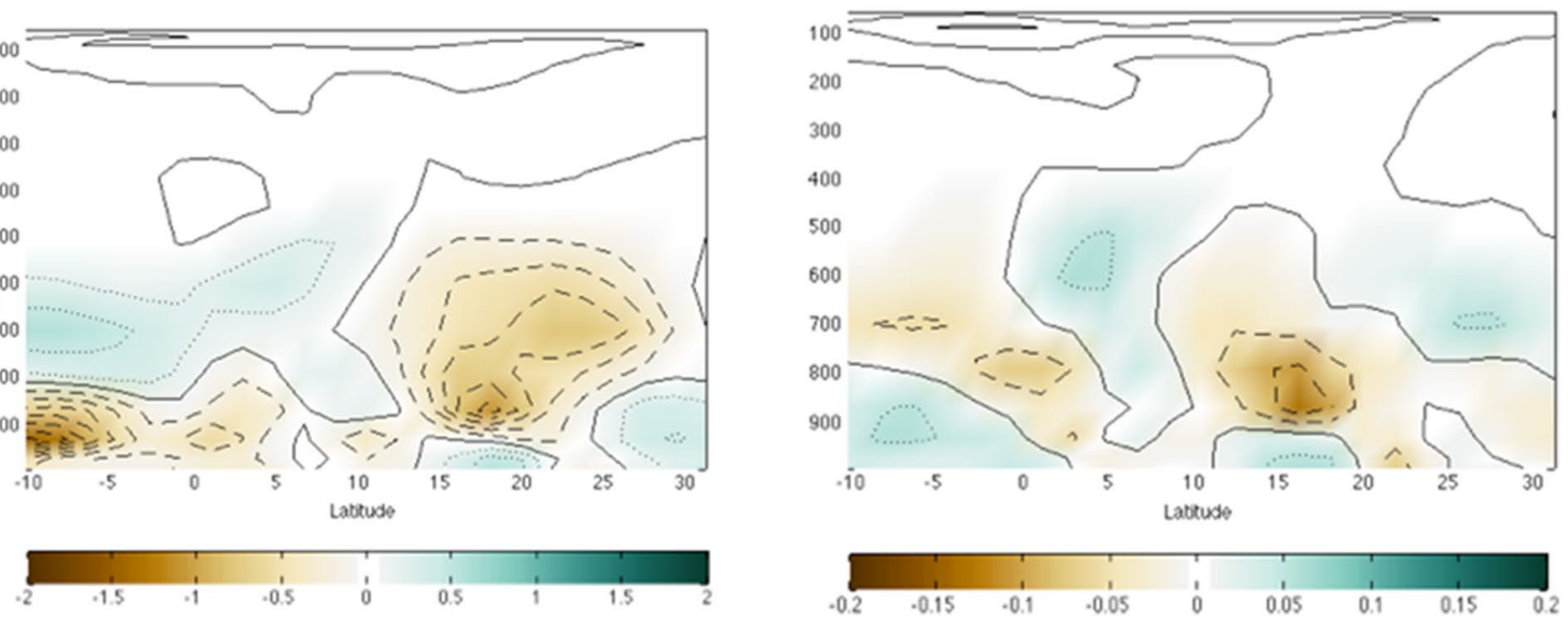

(f)

Fig. 12 JAS climatology (left panels) and dry-wet years difference (right panels) for $\mathbf{a}$ and $\mathbf{b}$ total moisture flux convergence, $\mathbf{c}$ and $\mathbf{d}$ mass convergence, $\mathbf{e}$ and $\mathbf{f}$ advection of specific humidity as a function of latitude and pressure level. Contours are added to better distinguish areas of positive (i.e. convergence, dotted contours) and nega-

tive values (i.e. divergence, dashed contours). The contour interval is from -2 to 2 by 0.2 for the left panels and -0.2 to 0.2 by 0.05 for the right panels. The zero contour is shown as a solid black line. All terms are in $\mathrm{mm} /$ day. Note the difference in scale for each column 
divergence more than outbalances the small surface convergence below (Fig. 12f). This represents a strengthening and equatorward movement of the heat low as well as the northern edge of precipitation compared to the climatology.

\section{Discussion and conclusions}

In this study we find that both the magnitude and the pattern of decadal scale precipitation variability in sub-Saharan Africa are realistically depicted in a SST-forced long integration of CAM4, albeit with some spatial biases. This spatial resemblance as well as the alikeness in the simulated time evolution of the precipitation response to SST compared to the observed evolution, in particular during the late 1960's decadal Sahelian precipitation shift, serves as impetus for using the model output in order to provide relevant information for studying mechanisms governing the decadal changes in sub-Saharan hydroclimate. This confirms a similar conclusion regarding using CAM4 in Sahel hydroclimate variability by Cook et al. (2012). The same cannot be said about the NCEP/NCAR Reanalysis dataset, which is plagued with serious biases that span the critical time interval.

Using the results of the MCA and a SST forced AGCM, we find that the warming in the Indian Ocean and relative cooling in the Northern Tropical Atlantic and warming in the Southern Tropical Atlantic played a role in causing the twentieth century Sahel drought. This finding is consistent with previous studies using different models for analysis (Bader and Latif 2003; Lu and Delworth 2005; Lu 2009; Hoerling et al. 2006) and helps to point to the robust relationship among anomalies in these basins and decadal scale precipitation variability regardless of the particular model used.

Our results support the notion that a relatively cool tropical Northern Atlantic compared to a relatively warm tropical Southern Atlantic Ocean shifts the axis of the ITCZ and the maximum rainfall in the western Sahel slightly southward relative to the climatologic ITCZ latitude. Furthermore, the drying is mostly accounted for by increased moisture divergence of the mean monthly flow, which is related to anomalous mass divergence in the air column where there would otherwise be convergence. This result is partly simply consistent with the change in P-E and cannot be viewed as causal. However, some of the changes in mass divergence patterns could have resulted from the teleconnection with convergence over the Indian Ocean and subsidence over West Africa due to Rossby wave dynamics. Changes in the moisture budget are also associated with a change in the intensity and position of the near-surface heat low, which further increased the supply of dry air to the Sahel from the north. We also find that the response of the advection of specific humidity is to drive moisture out of the continent following the subsiding and diverging motion at mid-levels, thus further depriving the Sahel of moisture necessary for precipitation. The role of the transient motions seems important as they persistently act to weakly dry the Sahel across the continent, where in the climatology they largely converge air over the region.

We corroborate the above explanations for the western Sahel, by showing changes in the Saharan heat low, wind fields, and moisture budget component terms. A weakening of the heat low occurs simultaneously with decreased precipitation in the western Sahel, which is consistent with increased subsidence and a slight increase in surface convergence. The shallow convection that occurs does not produce precipitation, being limited in height to approximately $900 \mathrm{mb}$. Furthermore, the behavior of the advection term does not greatly differ between the climatology and the dry period; there still remains positive specific humidity advection around $\sim 12^{\circ}-20^{\circ} \mathrm{N}$, defining the Sahel itself. This subtly points to the interpretation of the local convergence patterns in a column integrated sense as being more important for the differences seen in the dry period. We interpret the behavior of the model ensemble average variables as being related to the warm phasing of the tropical Southern Atlantic and Indian Oceans shown in the MCA analysis and thought to increase sea level pressure over the Sahara through Rossby wave radiation and to stabilize the upper atmosphere by transferring heat aloft in these areas via deep convection ( $\mathrm{Lu} 2009$ ). Thus, in answering our original questions posed in this study, we find that the atmospheric circulation changes forced by the warming of the Indian Ocean and the dipole pattern of the Atlantic basin help explain the Sahelian drought of the mid-twentieth century, particularly in the western Sahel. In the model, drying over the northern Sahel is enhanced by reduced evaporation indicative of a land surface feedback on reduced precipitation.

Obviously, other timescales of importance exist when studying Sahelian rainfall variability. A companion paper is being developed that aims to apply the same moisture budget framework to interannual variability to provide insight for the mechanisms operating on shorter timescales. Further work could also be done in order to study whether the same terms that dominate overall P-E natural variability are also at work in explaining the climate change projections for this region. In other words, if the Sahel is expected to become wetter in the future, do the models show increased mass convergence dominating the signal in the area, consistent with the arguments outlined above? Or will this trend be dominated by increased specific humidity advection, essentially a certainty as the atmosphere continues to warm? Such a study compared to the results of this work would help to facilitate understanding of the character of natural precipitation variability in the region 
and differing mechanisms due to climate change. Finally, this study lacks the ability to claim causality because of the use of a diagnostic moisture budget approach. However, we believe that the behavior detailed through the use of the moisture budget equation in this region is consistent with expectation from SST warming shown and provides a new scope under which to continue to study precipitation changes in the Sahel.

Acknowledgments The authors would like to thank Dr. Jennifer Nakamura for providing assistance with data analysis as well as Drs. Naomi Henderson, Haibo Liu, and Richard Seager and the Global Decadal Hydroclimate Predictability, Variability, and Change (Glo$\mathrm{DecH})$ group with its support through the National Oceanic and Atmospheric Association (NOAA) for useful discussions and completion of the model runs. CP would also like to thank the National Science Foundation for funding through the Graduate Research Fellowship Program and Etienne Dunn-Sigouin for assistance with programming. Finally, we thank the editor and an anonymous reviewer for providing useful comments that improved this study.

\section{Appendix}

Figure 3 from the manuscript clearly shows the overestimation of rainfall variability in the NCEP/NCAR Reanalysis when compared to the observations or CAM4 modeled precipitation. It is further shown here that this discrepancy is due to the overestimation of the variance in the precipitation field prior to 1968 (Fig. 13a), and that it is much more realistic afterwards (Fig. 13b).

Given the documented discrepancies in the variability of the NCEP/NCAR Reanalysis data (Poccard et al.
2000; Kintner et al. 2004), an alternative method to utilize the moisture budget of this dataset would be to compute the precipitation as a summation of the column integrated moisture flux and the evaporation, as explained in the text. However, a quick glance at Fig. 14 clearly shows that virtually all moisture budget variables through time (1901-2008, unfiltered) seem to show the same discrepancies as the previous studies have indicated. These include surface evaporation (in $\mathrm{W} / \mathrm{m}^{2}$ ), total column precipitable water (in $\mathrm{kq} / \mathrm{m}^{2}$ ), specific humidity (at 925 , 600 , and $300 \mathrm{mb}$ and unitless), and zonal and meridional wind velocity (at 925,600 , and $300 \mathrm{mb}$ in $\mathrm{m} / \mathrm{s}$ ). In virtually all cases, not just limited to precipitation and wind fields as documented by previous works, but also with evaporation, specific humidity, and total column precipitable water, the troubling drop off in magnitude and variability is apparent (note the differences in scale among the various panels). All variables reveal similar patterns to the NCEP/NCAR Reanalysis generated spurious precipitation field (Fig. 14a). There is a huge dropoff in the magnitude of all the study variables around 1968, with concurrent decreases in all moisture budget terms' variability. This brief exploratory analysis, along with the results of previous works, leads us to conclude that studying regional variations in Sahel rainfall previous to 1968 cannot be done accurately using the NCEP/NCAR Reanalysis fields, even if the precipitation is computed as a residual of other variables' due to their apparent shortcomings as well. This finding further encourages us to use the SST-driven model to understand the twentieth century moisture budget and its variability.
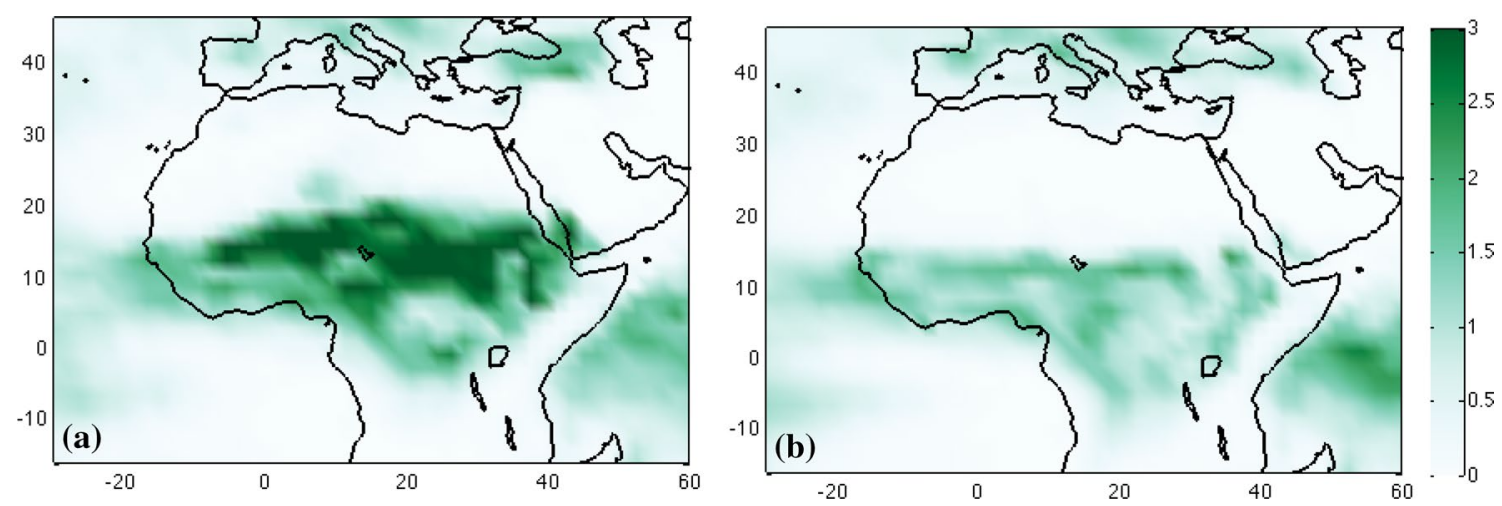

Fig. 13 JAS precipitation root mean square anomaly (mm/day) in a NCEP/NCAR 1949-1967 and b 1968-2008 

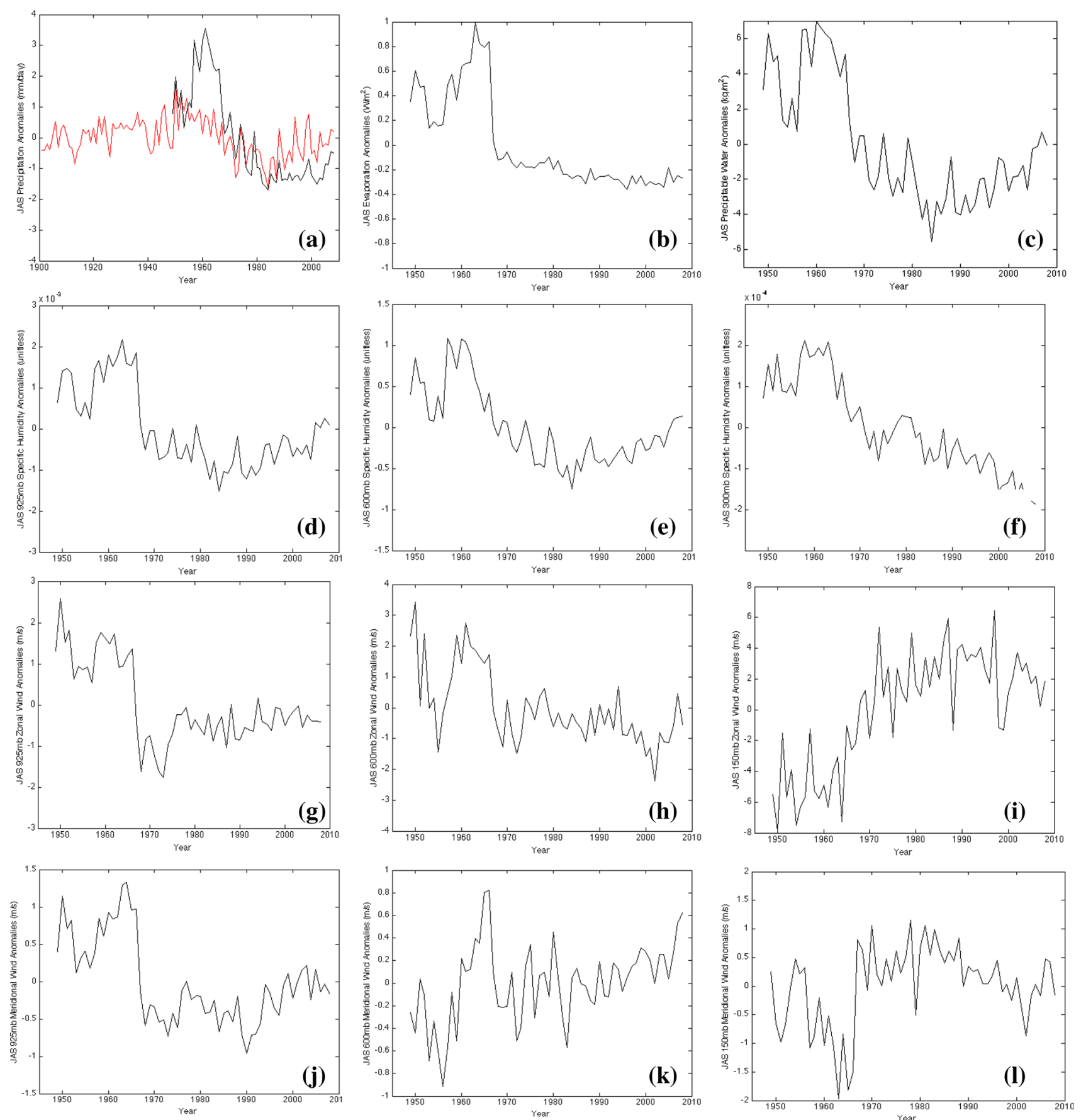

Fig. 14 NCEP/NCAR Reanalysis variables averaged over the Sahel domain for JAS 1901-2008. a Precipitation, including UEA observations (red line), $\mathbf{b}$ evaporation, $\mathbf{c}$ precipitable water, $\mathbf{d}-\mathbf{f}$ specific

\section{References}

Ali A, Lebel T (2009) The Sahelian standardized rainfall index revisited. Int J Climatol 29:1705-1714

Bader J, Latif M (2003) The impact of decadal-scale Indian Ocean sea surface temperature anomalies on Sahelian rainfall and the North Atlantic oscillation. Geophys Res Lett 30(22):2169. doi:10.1029 /2003GL018426 humidity at 925,600 , and $300 \mathrm{mb}, \mathbf{g}-\mathbf{i}$ zonal wind at 925,600 , and $150 \mathrm{mb}$, and $\mathbf{j}-\mathbf{-}$ meridional wind at 925,600 , and $150 \mathrm{mb}$. Scales differ among all plots

Biasutti M (2013) Forced Sahel rainfall trends in the CMIP5 archive. J Geophys Res 118:1613. doi:10.1002/jgrd.50206

Biasutti M, Sobel AH, Camargo SJ (2009) The role of the Sahara Low in summertime Sahel Rainfall variability and change in the CMIP3 models. J Clim 22:5755-5771

Bretherton CS, Smith C, Wallace JM (1992) An intercomparison of methods for finding coupled patterns in climate data. J Clim $5: 541-560$ 
Brubaker KL, Entekhabi A, Eagleson PS (1993) Estimation of continental precipitation recycling. J Clim 6:1077-1089

Caminade C, Terray L (2010) Twentieth century Sahel rainfall variability as simulated by the ARPEGE AGCM, and future changes. Clim Dyn 35:75-94

Charney J (1975) Dynamics of deserts and drought in the Sahel. Q J R Meteorol Soc 101:193-202

Cook KH, Meehl GA, Arblaster JM (2012) Monsoon Regimes and Processes in CCSM4. Part II: African and American monsoon systems. J Clim 25:2609-2621

Folland CK, Palmer TN, Parker DE (1986) Sahel rainfall and worldwide sea temperatures, 1901-1985. Nature 320:602-607

Fontaine B, Louvet S, Roucou P (2008) Definition and predictability of an OLR-based West African monsoon onset. Int J Climatol 28:1787-1798

Gent et al (2011) The community climate system model version 4. J Clim 24:4973-4991

Giannini A, Saravanan R, Chang P (2003) Oceanic forcing of Sahel rainfall on interannual to interdecadal time scales. Science 302:1027-1030

Giannini A, Saravanan R, Chang P (2005) Dynamics of the boreal summer African monsoon in the NSIPP1 atmospheric model. Clim Dyn 25:517-535

Grist JP, Nicholson SE (2001) A study of the dynamic factors influencing the rainfall variability in the West African Sahel. J Clim 14:1337-1359

Hagos SM, Cook KH (2007) Dynamics of the West African monsoon jump. J Clim 20:5264-5284

Hagos SM, Cook KH (2008) Ocean warming and late-twentieth-century Sahel drought and recovery. J Clim 21:3797-3814

Hagos SM, Zhang C (2010) Diabatic heating, divergent circulation and moisture transport in the African monsoon system. Q J R Meteorol Soc 136:411-425

Hoerling M, Hurrell J, Eischeid J, Phillips A (2006) Detection and attribution of twentieth-century Northern and Southern African rainfall change. J Clim 19:3989-4008

Janowiak J, Grubber A, Kondragunta CR, Livezey R, Huffman G (1998) A comparison of the NCEP/NCAR reanalysis precipitation and the GPCP raingauge-satellite combined dataset with observational error considerations. J Clim 11:2960-2979

Kalnay E et al (1996) The NCEP/NCAR 40-year reanalysis project. Bull Am Meteorol Soc 77:437-471

Kintner JL-III, Fennessy MJ, Krishnamurthy V, Marx L (2004) An evaluation of the apparent interdecadal shift in the tropical divergent circulation in the NCEP-NCAR reanalysis. J Clim $17: 349-361$

Lu J (2009) The dynamics of the Indian Ocean sea surface temperature forcing of Sahel drought. Clim Dyn 33:445-460

Lu J, Delworth TL (2005) Oceanic forcing of the late 20th Century Sahel drought. Geophys Res Lett 32:22706. doi:10.1029/200 5GL023316

Mitchell T, Jones P (2005) An improved method of constructing a database of monthly climate observations and associated highresolution grids. Int J Clim 25:693-712

Nicholson SE (2000) The nature of rainfall variability over Africa on time scales of decades to millennia. Glob Plan Change 26:137-158
Nicholson SE (2005) On the question of the "recovery" of the rains in the West African Sahel. J Arid Environ 63:615-641

Nicholson SE, Webster PJ (2007) A physical basis for the interannual variability of rainfall in the Sahel. Q J R Meteorol Soc 133:2065-2087

Otto-Bliesner B (1999) El Nino/La Nina and Sahel precipitation during the middle Holocene. Geophys Res Lett 26:87-90

Palmer TN (1986) Influence of the Atlantic, Pacific, and Indian Oceans on Sahel rainfall. Nature 322:251-253

Poccard I, Janicot S, Camberlin P (2000) Comparison of rainfall structures between NCEP/NCAR reanalyses and observed data over tropical Africa. Clim Dyn 16:897-915

Rayner NA, Parker DE, Horton EB, Folland CK, Alexander LV, Rowell DP, Kent EC, Kaplan A (2003) Global analyses of sea surface temperature, sea ice, and night marine air temperature since the late nineteenth century. J Geophys Res 108(D14):4407. doi:10.10 29/2002JD002670

Rowell DP, Folland CK, Maskell K, Ward MN (1995) Variability of summer rainfall over tropical north Africa (1906-92): observations and Modelling. Q J R Meteorol Soc 121:669-704

Salack S, Muller B, Gaye AT (2011) Rain-based factors of high agricultural impacts over Senegal. Part I: integration of local to subregional trends and variability. Theor Appl Climatol 106:1-22

Seager R, Henderson N (2013) Diagnostic computation of moisture budgets in the ERA-interim reanalysis with reference to analysis of CMIP-archived atmospheric model data. J Cim 26:7876-7901

Seager R, Naik N, Vecchi GA (2010) Thermodynamic and dynamic mechanisms for large-scale changes in the hydrological cycle in response to global warming. J Clim 23:4651-4668

Seager R, Pederson N, Kushnir Y, Nakamura J (2012) The 1960s drought and the subsequent shift to a wetter climate in the catskill mountains region of the New York City watershed. J Clim 25:6721-6742

Shanahan TM, Overpeck JT, Anchukaitis KJ, Beck JW, Cole JE, Dettman DL, Peck JA, Scholz CA, King JW (2009) Atlantic forcing of persistent drought in West Africa. Science 324:377-380

Su H, Neelin JD (2005) Dynamical mechanisms for African monsoon changes during the mid-Holocene. J Geophys Res 110:D19105. doi:10.1029/2005JD005806

Taylor CM, Lambin EF, Stephenne N, Harding RJ, Essery RL (2002) The influence of land use change on climate in the Sahel. J Clim 15:3615-3629

Trenberth KE, Guillemot CJ (1995) Evaluation of the global atmospheric moisture budget as seen from analysis. J Clim 8:2255-2272

Trenberth KE, Dai A, Rasmussen RM, Parsons DB (2003) The changing character of precipitation. Bull Am Meteorol Soc $84: 1205-1217$

Uppala SM et al (2005) The ERA-40 re-analysis. Q J R Meteorol Soc 131:2961-3012

Zeng N, Neelin JD, Lau K-M, Tucker CJ (1999) Enhancement of interdecadal climate variability in the Sahel by vegetation interaction. Science 286:1537-1540 